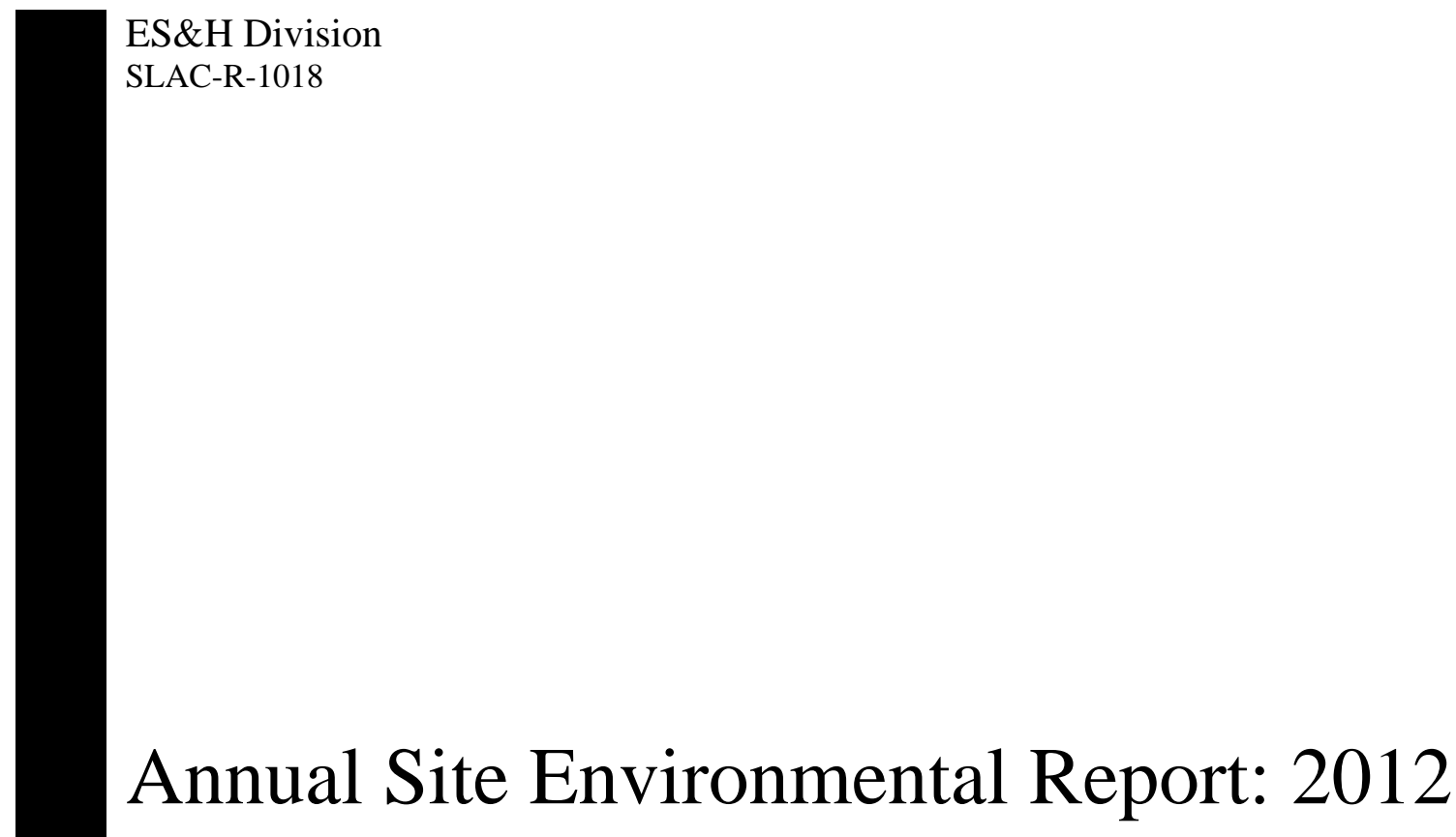

September 2013

Prepared for the Department of Energy under contract number DE-AC02-76-SF00515

SLAC National Accelerator Laboratory, Stanford University, Stanford, CA 94309

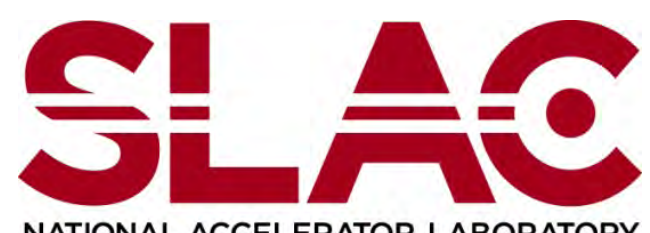

NATIONAL ACCELERATOR LABORATORY 


\section{Disclaimer}

This document, and the material and data contained therein, was developed under sponsorship of the United States Government. Neither the United States nor the Department of Energy, nor the Leland Stanford Junior University, nor their employees, makes any warranty, express or implied, or assumes any liability or responsibility for accuracy, completeness, or usefulness of any information, apparatus, product, or process disclosed, or represents that its use will not infringe privately owned rights. Mention of any product, its manufacturer, or suppliers will not, nor is it intended to, imply approval, disapproval, or fitness for any particular use. A royalty-free, non-exclusive right to use and disseminate same, for any purpose whatsoever, is expressly reserved to the United States and the university.

\section{Publication Data}

This document was designed and published by Environmental Safety \& Health (ES\&H) ${ }^{1}$ Division Publishing

Document Title: Annual Site Environmental Report: 2012

Original Publication Date: September 2013

Original Source: ES\&H Division

Document Number: SLAC-R-1018

Prepared for the United States Department of Energy under contract DE-AC02-76-SF00515 This report is available on line at: https://www-internal.slac.stanford.edu/scidoc/docMeta.aspx?slacPubNumber=slac-R-1018

Printed copies can be obtained by United States Department of Energy employees and contractors from the Office of Scientific and Technical Information, 1 Science.gov Way, Oak Ridge, TN 37831 and by the public from the National Technical Information Service, United States Department of Commerce, 5301 Shawnee Road, Alexandria, VA 22312.

Comments on the report may be sent to

ES\&H Publishing Coordinator

eshpubs@slac.stanford.edu

Mailstop 84

SLAC National Accelerator Laboratory

2575 Sand Hill Road

Menlo Park, CA 94025

Additional information about SLAC National Accelerator Laboratory is available at http://www.slac.stanford.edu/

1 A reorganization of SLAC during 2013 combined the ES\&H Division with parts of the Office of Planning and Assessment into the new Environment, Safety, Health and Quality Division. However, since the time period for this report is calendar year 2012, ES\&H will be used throughout the report. 


\title{
(0) ENNERGY
}

\author{
SLAC Site Office \\ SLAC National Accelerator Laboratory \\ 2575 Sand Hill Road, MS-8A \\ Menlo Park, CA 94025
}

September 17, 2013

Subject: 2012 Annual Site Environmental Report (ASER) for the SLAC National Accelerator Laboratory

This report, prepared by the SLAC National Accelerator Laboratory (SLAC) for the U.S. Department of Energy (DOE), SLAC Site Office (SSO), provides a comprehensive summary of the environmental program activities at SLAC for calendar year 2012. Annual Site Environmental Reports (ASERs) are prepared for all DOE sites with significant environmental activities, and distributed to relevant external regulatory agencies and other interested organizations or individuals.

To the best of my knowledge, this report accurately summarizes the results of the 2012 environmental monitoring, compliance, and restoration programs at SLAC. This assurance can be made based on SSO and SLAC review of the ASER, and quality assurance protocols applied to monitoring and data analyses at SLAC.

Any questions or comments regarding this report may be directed to Dave Osugi of the SSO at (650) $926-3305$, or by mail to the address above.

Sincerely,

SIGNATURE ON FILE

Paul Golan

Site Manager

SLAC Site Office 


\section{Contents}

Disclaimer

Publication Data

Contents $\quad$ i

Figures $\quad$ v

Tables $\quad$ vi

Appendices vii

Preface viii

Organization viii

Contributors $\quad$ ix

Primary Coordinators and Authors $\quad$ ix

Additional Reviewers and/or Authors ix

Editing and Publishing $\quad$ ix

Acronyms $\quad x$

$\begin{array}{ll}\text { Executive Summary } & \text { ES-1 }\end{array}$

1 Site Overview $1-1$

1.1 Introduction $1-1$

1.1.1 SLAC Mission $1-1$

1.1.2 Research Program 1-1

1.2 Location $1-3$

1.3 Climate $1-3$

1.4 Land Use $1-3$

1.5 Water Supply $1-3$

1.6 Geology 1-4

1.7 Demographics $1-4$

2 Environmental Compliance 2-1

2.1 Introduction 2-1

2.2 Regulatory Framework 2-1

2.3 Environmental Permits and Notifications 2-1

2.4 Environmental Incidents $2-2$

2.4.1 Non-radiological Incidents $\quad 2-2$

2.4.2 Radiological Incidents $\quad 2-2$

2.5 Assessments, Inspections and Quality Assurance 2-2

2.5.1 Assessments 2-2 
2.5.2 Inspections $2-3$

2.5.3 Quality Assurance 2-3

3 Management Systems 3-1

3.1 Introduction 3-1

3.2 SLAC Organization 3-1

3.3 ES\&H Division Organization 3-1

3.3.1 Environmental Protection Department 3-1

3.3.2 Field Services Department 3-1

3.3.3 Security and Emergency Management Department 3-2

3.3.4 Radiation Protection Department 3-2

3.3.5 Project Safety Department 3-2

3.3.6 Training and Information Management Department 3-3

3.4 Integrated Safety and Environmental Management System 3-3

3.4.1 Integrated Safety and Environmental Management System 3-3

3.4.2 Requirements Management System 3-3

3.4.3 Environmental Performance Measures 3-3

3.4.4 Training 3-4

3.5 Environmental Management System $3-4$

4 Environmental Non-radiological Programs $4-1$

4.1 Introduction 4-1

4.2 Air Quality Management Program 4-1

4.2.1 Regulatory Framework $\quad$ 4-2

4.2.2 Program Status 4-2

4.3 Industrial and Sanitary Wastewater Management Program 4-4

4.3.1 Regulatory Framework 4-4

4.3.2 Program Status 4-5

4.4 Surface Water Management Program 4-6

4.4.1 Regulatory Framework $\quad$ 4-7

4.4.2 Program Status $\quad$ 4-7

4.5 Hazardous Materials Management 4-9

4.5.1 Regulatory Framework 4-9

4.5.2 Program Status 4-9

4.5.3 Hazardous Materials Business Plan Program 4-10

4.5.4 Toxics Release Inventory Program 4-10

4.5.5 California Accidental Release Prevention Program 4-11

4.5.6 Aboveground Storage Tank Program 4-11 
4.5.7 Toxic Substances Control Act Program 4-12

4.5.8 Chemical Management System 4-12

4.6 Waste Management and Minimization 4-12

4.6.1 Hazardous Waste Management and Minimization 4-13

4.6.2 Non-Hazardous Waste Management and Minimization 4-14

4.6.3 Other Waste Management Activities $\quad$ 4-15

4.7 Sustainability 4-16

4.7.1 Progress on Sustainability Goals $\quad$ 4-16

4.8 Environmental Planning 4-18

4.8.1 SLAC Long Range Development Plan 4-19

4.8.2 National Environmental Policy Act 4-19

5 Environmental Radiological Program $\quad$ 5-1

5.1 Introduction $\quad$ 5-1

5.2 Sources of Radiation and Radioactivity

5.3 Monitoring for Direct Radiation $\quad$ 5-2

5.4 Assessment of Airborne Radioactivity 5-2

5.5 Assessment of Radioactivity in Wastewater 5-3

5.5.1 Industrial Water $5-3$

5.5.2 Stormwater

5.5.3 Groundwater 5-5

5.6 Assessment of Radioactivity in Soil 5-5

5.7 Release of Property Containing Residual Radioactive Material 5-6

5.8 Potential Dose to the Public 5-6

5.9 Biota Dose $\quad 5-8$

5.9.1 Dose to Biota from Direct Radiation 5-8

5.9.2 Dose to Biota from Activation Products $\quad$ 5-8

5.10 Low-level Radioactive Waste Management 5-8

6 Groundwater Protection and Environmental Restoration 6-1

6.1 Introduction 6-1

6.2 Background Conditions 6-1

6.3 Areas with Potential Impact from Chemicals 6-1

6.4 Strategies for Controlling Potential Sources of Chemicals 6-2

6.5 Restoration Activities 6-2

6.6 Regulatory Framework 6-2

6.7 Groundwater Characterization Monitoring Network 6-3

6.8 Site Descriptions and Results 6-8 
6.8.1 Former Solvent Underground Storage Tank

6.8.2 Former Hazardous Waste Storage Area

6.8.3 Plating Shop

6-10

6.8.4 Test Lab and Central Lab

6.8.5 Beam Dump East

6-10

6.8.6 Lower Salvage Yard

6-11

6.8.7 Removal Actions

6-11

6.9 Excavation Clearance Program

6-11 


\section{Figures}

Figure 1-1 SLAC Site Location $\quad$ 1-2

Figure 1-2 Site Area General Geographic and Geologic Setting 1-4

Figure 4-1 Industrial and Sanitary Wastewater Monitoring Locations 4-5

Figure 4-2 Surface Water Monitoring Locations $\quad$ 4-7

Figure 4-3 Routine Hazardous Waste Generation, 2002-2012 4-14

Figure 4-4 Municipal Solid Waste Recycling and Disposal, 2002-2012 4-16

Figure 6-1 Groundwater Characterization Monitoring Network 6-5

Figure 6-2 Westside Groundwater Network and Impacted Areas 6-6

Figure 6-3 Eastside Groundwater Network and Impacted Areas 6-7 


\section{Tables}

Table 2-1 General Permits Held by SLAC $\quad$ 2-1

Table 2-2 Environmental Audits and Inspections $\quad$ 2-3

Table 4-1 Recent Environmental Awards $\quad$ 4-1

Table 4-2 Stormwater Parameters Analyzed 4-8

Table 4-3 Aboveground Petroleum Tanks $\quad$ 4-11

Table 4-4 Hazardous Waste Treatment Units Subject to Tiered Permitting 4-13

Table 4-5 Progress against Select Sustainability Goals of EO 13423/13514 through FY 2012 4-17

Table 5-1 Activation Products in Water or Air $5-1$

Table 5-2 Airborne Radioactivity Released in CY 2012

Table 5-3 Radioactivity in Wastewater Released into Sanitary Sewer CY 2012 5-4

Table 5-4 Summary of Radioactivity in SLAC Wastewater, CY 2002-2012 5-4

Table 5-5 Summary of Tritium Concentrations Measured in Four Monitoring Wells in CY 2012 5-5

Table 5-6 Summary of Potential Annual Doses due to SLAC Operations in CY 2012

Table 5-7 Potential Annual Dose (mrem/yr) to Maximally Exposed Individual, CY 2002-2012 5-7

Table 6-1 RWQCB Order Deliverables Status $\quad$ 6-3

Table 6-2 Monitoring Locations and Number of Wells 6-8 


\section{Appendices}

A Distribution List 


\section{Preface}

To satisfy the requirements of the United States Department of Energy Order 231.1, "Environment, Safety and Health Reporting", the Environment, Safety, and Health Division of the SLAC National Accelerator Laboratory prepares an annual report describing its environmental programs and activities.

This Annual Site Environmental Report: 2012 summarizes the SLAC National Accelerator Laboratory compliance with standards and requirements, describes the management and monitoring systems in place, and highlights significant accomplishments for the year.

\section{Organization}

The report is published in a single volume, organized into the following chapters:

Chapter 1, "Site Overview", describes the environmental setting of the SLAC National Accelerator Laboratory and the activities conducted at the site

Chapter 2, "Environmental Compliance”, gives an account of the regulatory framework and results concerning the site's environmental programs

Chapter 3, "Management Systems", outlines the organizational structure, methods, and responsibilities relevant to environmental programs

Chapters 4, 5, and 6, respectively "Environmental Non-radiological Programs”, "Environmental Radiological Programs”, and “Groundwater Protection and Environmental Restoration”, give more detailed accounts of the programs and their results for the year

An executive summary provides an overview of the report. 


\title{
Contributors
}

This report was prepared under the direction of Helen Nuckolls, ES\&H Division, Environmental Protection Department.

\section{Primary Coordinators and Authors}

Ivy Chan (Chapter 5)

Micki De Camara (Chapters 3 and 4)

Ryan Ford (Chapter 5)

April Giangerelli (Chapters 3 and 4)

Mike Hug (Chapter 4)

Greg Johnson (Chapter 4)

Olga Ligeti (Chapter 5)

Adam Ng (Chapter 6)

Dellilah Sabba (editor, executive summary, Chapters 1, 2, 3 and 6)

Kirk Stoddard (Chapter 4)

\section{Additional Reviewers and/or Authors}

\author{
Janet Argyres \\ James Liu \\ Helen Nuckolls \\ Sayed Rokni \\ James Tarpinian \\ Susan Witebsky
}

\section{Editing and Publishing}

ES\&H Division Publishing edited and published this report. 


\begin{tabular}{|c|c|}
\hline${ }^{3} \mathrm{H}$ & tritium \\
\hline $\mathrm{AB}$ & Assembly Bill \\
\hline AOC & Area of Concern \\
\hline ASER & Annual Site Environmental Report \\
\hline ASTs & aboveground storage tanks \\
\hline BAAQMD & Bay Area Air Quality Management District \\
\hline BaBar & SLAC B-Factory detector \\
\hline $\mathrm{BDE}$ & beam dump east \\
\hline BMP & best management practice \\
\hline CD-2 & Critical Decision 2 \\
\hline$C \& D$ & construction and demolition \\
\hline CalARP & California Accidental Release Prevention Program \\
\hline CARB & California Air Resources Board \\
\hline CERCLA & Comprehensive Environmental Response, Compensation, and Liability Act \\
\hline CFR & Code of Federal Regulations \\
\hline CHWMA & centralized hazardous waste management area \\
\hline $\mathrm{Ci}$ & curie \\
\hline CMS & chemical management system \\
\hline COPC & chemical of potential concern \\
\hline $\mathrm{CPE}$ & C/P/E Environmental Services, LLC, of Atlanta, Georgia \\
\hline CUPA & certified unified program agency \\
\hline CWA & Clean Water Act \\
\hline CY & calendar year \\
\hline CX & categorical exclusion \\
\hline DOE & United States Department of Energy \\
\hline DPE & dual-phase extraction \\
\hline DWS & drinking water standard \\
\hline E85 & blend of fuel where 85 percent is ethanol and 15 percent is gasoline \\
\hline EA & environmental assessment \\
\hline EBR & Environmental Baseline Report \\
\hline
\end{tabular}




\begin{tabular}{|c|c|}
\hline EM & environmental management \\
\hline EMS & environmental management system \\
\hline $\mathrm{EO}$ & Executive Order \\
\hline EP & Environmental Protection Department \\
\hline EPCRA & Emergency Planning and Community-Right-to-Know Act \\
\hline ERT & emergency response team \\
\hline ES\&H & environment, safety, and health \\
\hline FACET & Facility for Advanced Accelerator Experimental Tests \\
\hline FHWSA & former hazardous waste storage area \\
\hline FMS & flow metering station \\
\hline FONSI & Finding of No Significant Impact \\
\hline FS & Feasibility Study \\
\hline FSUST & former solvent underground storage tank \\
\hline FY & fiscal year \\
\hline GDF & gasoline dispensing facility \\
\hline GHG & greenhouse gas \\
\hline GWP & global warming potential \\
\hline HAPs & hazardous air pollutants \\
\hline Haas & Haas Group International \\
\hline HPSB & high-performance sustainable building \\
\hline HMBP & hazardous materials business plan \\
\hline HMIS & hazardous materials inventory statement \\
\hline IAS & Integrated Assessment Schedule \\
\hline IDPE & interim dual-phase extraction \\
\hline INL & Idaho National Laboratory \\
\hline IR & interaction region \\
\hline ISEMS & integrated safety and environmental management system \\
\hline ISM & integrated safety management \\
\hline ISO & International Organization for Standardization \\
\hline JRBP & Jasper Ridge Biological Preserve \\
\hline $\mathrm{km}$ & kilometer \\
\hline $\mathrm{kW}$ & kilowatt \\
\hline $\mathrm{L}$ & liter \\
\hline lbs & pounds \\
\hline
\end{tabular}




\begin{tabular}{|c|c|}
\hline LEED & Leadership in Energy and Environmental Design \\
\hline linac & linear accelerator \\
\hline LCLS & Linac Coherent Light Source \\
\hline LLRW & low-level radioactive waste \\
\hline LRDP & long-range development plan \\
\hline LSY & lower salvage yard \\
\hline $\mathrm{M} \& \mathrm{O}$ & management and operating \\
\hline MAPEP & mixed-analyte performance evaluation program \\
\hline MBTUH & one-thousand British Thermal Units of Heat \\
\hline MEI & maximally exposed individual \\
\hline MFPF & metal finishing pre-treatment facility \\
\hline MGE & main gate east channel \\
\hline MPMWD & Menlo Park Municipal Water Department \\
\hline MPR & monitoring plan report \\
\hline mrem & millirem \\
\hline $\mathrm{mSv}$ & milli-Sievert \\
\hline na & not available \\
\hline $\mathrm{n} / \mathrm{a}$ & not applicable \\
\hline NA & north adit channel \\
\hline NEPA & National Environmental Policy Act \\
\hline NESHAP & National Emission Standards for Hazardous Air Pollutants \\
\hline NHPA & National Historic Preservation Act \\
\hline OPA & Office of Planning and Assessment \\
\hline OSHA & Occupational Safety and Health Administration \\
\hline OU & operable unit \\
\hline PAFD & Palo Alto Fire Department \\
\hline PBR & permit by rule \\
\hline PBVs & parameter benchmark values \\
\hline PCB & polychlorinated biphenyl \\
\hline PCGs & Preliminary Cleanup Goals \\
\hline $\mathrm{pCi} / \mathrm{L}$ & picoCuries per liter \\
\hline PEP & Positron-Electron Project \\
\hline ppm & parts per million \\
\hline PRGs & preliminary remediation goals \\
\hline
\end{tabular}




\begin{tabular}{|c|c|}
\hline PSA & plating shop area \\
\hline PV & photo-voltaic \\
\hline QA & quality assurance \\
\hline QC & quality control \\
\hline RA & risk assessment report \\
\hline RAP & remedial action plan \\
\hline RECs & Renewable Energy Certificate \\
\hline REP & Radiological Environmental Protection \\
\hline RCRA & Resource Conservation and Recovery Act \\
\hline $\mathrm{RD}$ & remedial design report \\
\hline RI & remedial investigation \\
\hline RMP & risk management plan \\
\hline $\mathrm{RP}$ & Radiation Protection Department \\
\hline RPFO & Radiological Protection Field Operations Group \\
\hline RWQCB & Regional Water Quality Control Board \\
\hline SARA & Superfund Amendments and Reauthorization Act \\
\hline SBSA & South Bayside System Authority \\
\hline Schnider ION & $\begin{array}{l}\text { meter developed by Schnider Electric that collects and analyzes data from a variety of } \\
\text { different brands of electric meters }\end{array}$ \\
\hline SHPO & State Historic Preservation Office \\
\hline $\mathrm{SF}_{6}$ & sulfur hexafluoride \\
\hline SLAC & SLAC National Accelerator Laboratory \\
\hline SME & subject matter expert \\
\hline SMOP & synthetic minor operating permit \\
\hline SMP & self-monitoring program \\
\hline SPCC & spill prevention, control, and countermeasures plan \\
\hline SPEAR & Stanford Positron-Electron Asymmetric Ring \\
\hline SSMP & Sanitary Sewer Management Plan \\
\hline SSO & DOE SLAC Site Office \\
\hline SSPP & Strategic Sustainability Performance Plan \\
\hline SSRL & Stanford Synchrotron Radiation Lightsource \\
\hline SUSB & Science and User Support Building \\
\hline SVOCs & semi-volatile organic compounds \\
\hline SWMP & stormwater monitoring program \\
\hline
\end{tabular}




$\begin{array}{ll}\text { SWPPP } & \text { stormwater pollution prevention plan } \\ \text { SWRCB } & \text { State Water Resources Control Board } \\ \text { TDS } & \text { total dissolved solids } \\ \text { TL/CL } & \text { test lab and central lab area } \\ \text { TPH } & \text { total petroleum hydrocarbons } \\ \text { TRI } & \text { toxic release inventory } \\ \text { TSCA } & \text { Toxic Substances Control Act } \\ \text { USEPA } & \text { United States Environmental Protection Agency } \\ \text { VOC } & \text { volatile organic compound } \\ \text { WBSD } & \text { West Bay Sanitary District } \\ \text { WM } & \text { Waste Management Group } \\ \text { WTS } & \text { waste tracking system } \\ \text { yr } & \text { year }\end{array}$




\section{Executive Summary}

This report provides information about environmental programs during calendar year 2012 at the SLAC National Accelerator Laboratory (SLAC) in Menlo Park, California. Activities that overlap the calendar year - e.g., stormwater monitoring covering the winter season of 2011/2012 (October 2011 through May 2012) - are also included.

Production of an annual site environmental report (ASER) is a requirement established by the United States Department of Energy (DOE) for all management and operating (M\&O) contractors throughout the DOE complex. SLAC is a federally funded research and development center managed and operated by Stanford University for the DOE.

Under Executive Order (EO) 13423, Strengthening Federal Environmental, Energy, and Transportation Management, EO 13514, Federal Leadership in Environmental, Energy, and Economic Performance, and DOE Order 436.1, Departmental Sustainability, SLAC effectively implements and integrates the key elements of an Environmental Management System (EMS) to achieve the site's integrated safety and environmental management system goals. For normal daily activities, SLAC managers and supervisors are responsible for ensuring that policies and procedures are understood and followed so that:

- Worker safety and health are protected

- The environment is protected

- Compliance is ensured

Throughout 2012, SLAC continued to improve its management systems. These systems provided a structured framework for SLAC to implement "greening of the government" programs required by EO 13423, EO 13514, and DOE Order 436.1. Overall, management systems at SLAC are effective, supporting compliance with all relevant statutory and regulatory requirements.

During 2012, many improvements were made in waste minimization, recycling, stormwater management, groundwater restoration, and SLAC's chemical management system (CMS). The following are among SLAC's environmental accomplishments for the year.

- SLAC recycled over 100 tons of scrap metal from the decommissioning of SLAC's B-Factory detector (BaBar) and Positron-Electron Project (PEP) II dismantling activities.

- $\quad$ SLAC completed the National Environmental Policy Act (NEPA) Environmental Assessment (EA) for the Linac Coherent Light Source-II (LCLS-II) project, a key milestone for DOE approval of the Critical Decision-2 (CD-2) for the project.

- SLAC completed the National Historic Preservation Act (NHPA) Section 106 consultation process with the State Historic Preservation Office (SHPO) for the Sector 10 LCLS-II X-ray laser injector support alcove, demolition of the cafeteria (Building 42) and the auditorium (Building 43) for construction of the Science and User Support Building (SUSB), and renovation of the Administration and Engineering building (Building 41).

- SLAC has made significant progress in the cleanup of legacy contamination of groundwater, by reducing the area of concern by over 80 percent in four areas and volatile organic compounds (VOCs) concentrations by over 99 percent in two areas. 
In addition, SLAC reduced its hazardous waste generated by routine operations from the 1993 baseline of 147 tons to 16 tons, an 89 percent reduction. The reduction has been achieved through a combination of waste minimization and pollution prevention techniques. SLAC also recycled 1,146 tons of municipal waste and disposed of 420 tons, equating to a diversion rate for municipal waste of 73 percent.

Among the improvements made in air quality, one of SLAC's two main boilers was replaced with a new unit and the other was upgraded with a new burner and control system. In addition, a permitted solventcleaning operation was discontinued. Finally, a permit-exempt operation, a plasma-arc cutting torch was decommissioned. By the end of 2012, SLAC managed a total of 62 sources of air emissions, of which 42 were permitted sources and 20 were exempt sources.

In 2012, there were no radiological impacts to the public or the environment from SLAC operations. The potential doses to the public were negligible and far below the regulatory and SLAC administrative limits. The dose that members of the public received due to SLAC operations is a very small fraction of the dose received from natural background radiation. No radiological incidents occurred that increased radiation levels to the public or released radioactivity to the environment. In addition to managing its radioactive wastes safely and responsibly, SLAC continued efforts to reduce the amount of routine wastes generated; resulting in a 37 percent reduction from calendar year 2011 levels. SLAC also continued its efforts to reduce the inventory of materials no longer needed for its mission by permanently removing 98 sealed radioactive sources from the inventory and the disposal of 539 cubic feet of low-level radioactive waste, five percent of which was legacy waste, to appropriate permitted and licensed treatment and disposal facilities for low-level radioactive waste.

SLAC is regulated under a site cleanup requirements order (Board Order) issued by the San Francisco Bay Regional Water Quality Control Board (RWQCB; Board Order number R2-2009-0072) on October 19, 2009, for the investigation and remediation of impacted soil and groundwater at SLAC. Risk-based preliminary cleanup goals for impacted soil and groundwater have been established for SLAC, and remediation efforts are being designed to meet these established goals. The Board Order also lists specific tasks and deadlines for completion of groundwater and soil characterization and other remediation activities. All deliverable submittals to the RWQCB in 2012 were completed and submitted on time. In 2012, SLAC Environmental Restoration Program personnel continued remediation efforts in specific areas impacted by chemicals of potential concern (COPC). From 2009 through 2011, interim soil removal actions were completed at 15 additional areas within SLAC. These removal actions resulted in the removal of approximately 35,000 cubic yards of impacted soil and debris. As of 2012, dual-phase extraction (DPE) systems, which involve the simultaneous extraction and treatment of chemically impacted groundwater and soil vapor, are operational at all four major areas within SLAC that have been impacted by COPCs in groundwater. Recent operating and monitoring data from the Test Lab/Central Lab (TL/CL) indicate that the remediation goals have been met. In December 2012, the RWQCB approved the shutdown of the TL/CL system for rebound testing. Operating data indicate that the remediation systems at the other locations have resulted in a decrease in concentrations of COPCs in groundwater and soil vapor and are achieving hydraulic control of the plumes. These remedial systems have also been demonstrated to provide effective hydraulic containment and remediation of COPCs in soil and groundwater. 


\section{Site Overview}

This chapter describes the environmental setting of SLAC and the activities conducted at the site.

The 2010 long-range development plan (LRDP) provides an overview of site environmental planning, including descriptions of environmental resources.

\subsection{Introduction}

SLAC is a national research laboratory operated by Stanford University under contract to the DOE. SLAC is located on the San Francisco Peninsula, about halfway between San Francisco and San Jose, California (Figure 1-1). Current research and scientific user facilities are in the areas of photon science, particle physics, particle astrophysics, accelerator physics, and accelerator research and development. Six scientists have been awarded the Nobel Prize for work carried out at SLAC, and there are 10 members of its faculty in the National Academies.

The majority of SLAC funding comes from the DOE Office of Science, with smaller contributions from the National Aeronautics and Space Administration, National Institutes of Health, and other federal and nonfederal sources. SLAC also receives funding from the DOE Office of Environmental Management (EM) for soil and groundwater investigation and remediation activities at the site, which are managed by SLAC for EM.

\subsubsection{SLAC Mission}

- Grow into a premier Photon Science laboratory

To make discoveries in photon science at the frontiers of the ultra small and ultrafast in a wide spectrum of physical and life sciences

- Pursue strategic programs in particle physics, particle astrophysics and cosmology

To make discoveries in particle physics and particle astrophysics that redefine humanity's understanding of what the universe is made of and the forces that control it

- Maintain our position as the premier accelerator laboratory

To continue to provide the most advanced accelerator technologies to the nation and the world

- Operate Safely / Train the Best

To operate a safe laboratory that employs and trains the best and brightest minds, helping to ensure the future economic strength and security of the nation

\subsubsection{Research Program}

SLAC has three major research areas: photon science, particle physics, and accelerator science and technology. In the photon science program, SLAC develops and supports innovative research instrumentation for X-ray based studies of matter on length scales below the nanometer level and on time scales from milli- down to femto-seconds. Photon science research encompasses such diverse elements as magnetic materials science, molecular environmental science, and structural biology; and the rapidly developing field of ultrafast X-ray science. 


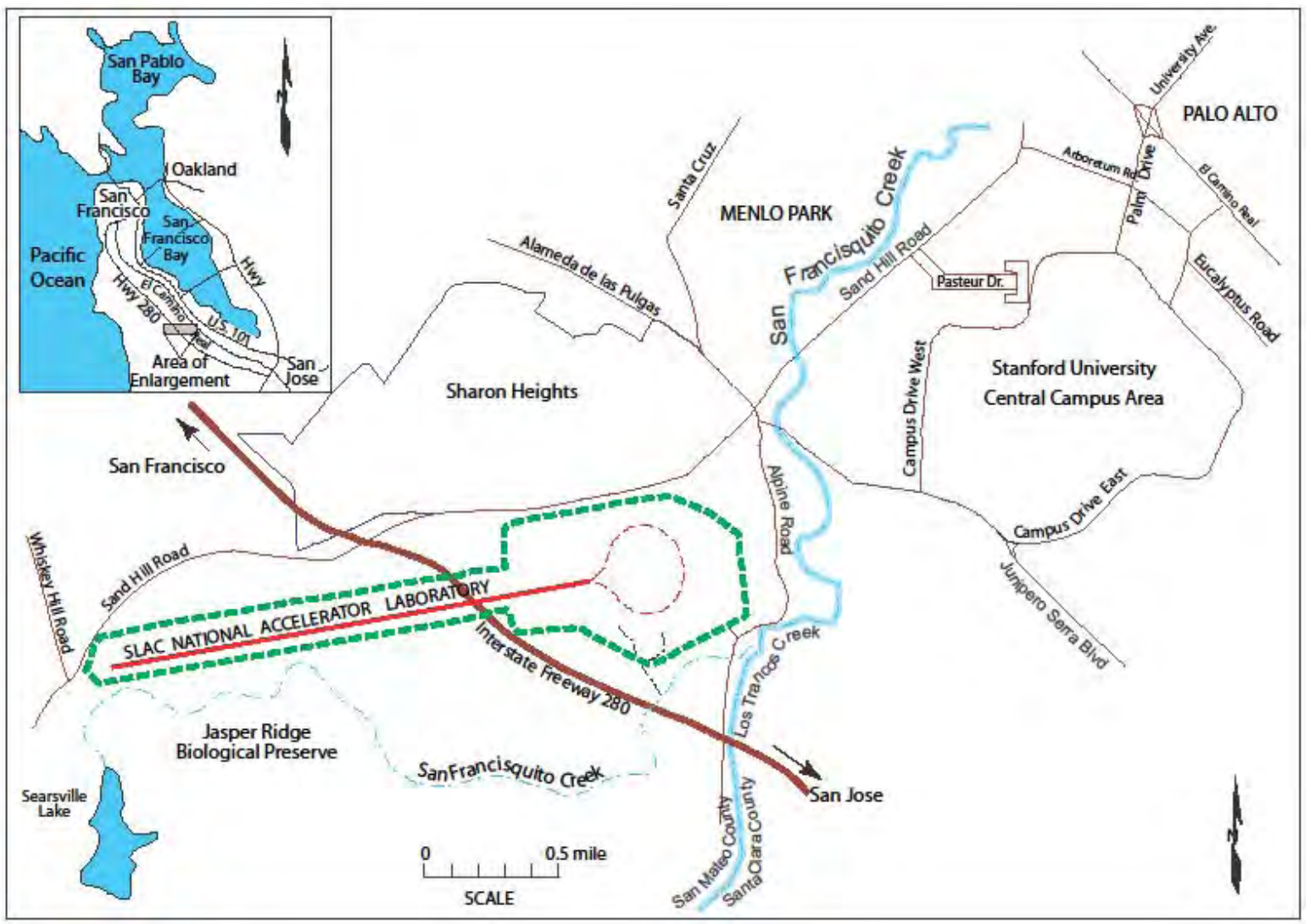

Figure 1-1 SLAC Site Location

The use of particle accelerators and observatories in space and on the ground helps us understand what our universe is made of at its most basic and fundamental level. The principal areas of particle physics studied at SLAC include the electron energy frontier using a linear collider, theoretical investigations of the quantum universe and, at the Kavli Institute for Particle Astrophysics and Cosmology, non-accelerator tests of the Standard Model through investigations of dark matter and dark energy.

The LCLS Directorate continues its experimental operations with the world's first hard X-ray free-electron laser that is exceeding all expectations.

SLAC supports other world-class research in physics, as well. The two-mile linear accelerator (linac) at SLAC, constructed in the early 1960s, generates high-intensity beams of electrons and positrons up to 50 billion electron volts. The linac is also used to inject electrons and positrons into colliding-beam storage rings for particle physics research. One of these storage rings, the Stanford Positron-Electron Asymmetric Ring (SPEAR), contains a separate, shorter linac and a booster ring for injecting accelerated beams of electrons. SPEAR is dedicated to synchrotron radiation research, and the synchrotron light it generates is used by the Stanford Synchrotron Radiation Lightsource (SSRL), a division of SLAC, to perform experiments. At SSRL, researchers work at the nanoscale frontier, making discoveries in solid-state physics, material science, environmental science, structural biology, and chemistry. In the past, researchers at SSRL have: looked at remnants of soft tissues in hundred million-year-old dinosaur fossils; mapped the distribution of elements in diseased brains; sought a deeper understanding of Alzheimer's and Parkinson's diseases; worked out the detailed structures of scores of proteins; and characterized the quantum electronic workings of new materials, leading the way toward the superconductors of the future. 


\subsection{Location}

SLAC is located in a belt of low, rolling foothills between the alluvial plain bordering San Francisco Bay to the east and the Santa Cruz Mountains to the west. The site varies in elevation from 175 to 380 feet above sea level. The alluvial plain to the east lies less than 151 feet above sea level; the mountains to the west rise abruptly to over 2,000 feet.

The site occupies 426 acres of land owned by Stanford University. The property was originally leased by Stanford University in 1962 to the U.S. Atomic Energy Commission, the predecessor to the DOE, for purposes of research into the basic properties of matter. The DOE and Stanford University signed a new lease which extends through 2043. The land is part of Stanford's academic preserve, and is located west of the university and the city of Palo Alto in an unincorporated portion of San Mateo County.

The site lies between Sand Hill Road and Alpine Road, bisected by Highway 280, on an elongated parcel roughly 2.75 miles long, oriented in an east-west direction. The parcel widens to about 0.6 miles at the target (east) end to allow space for buildings and experimental facilities. The south side of much of the western end of the parcel is bordered by Stanford University's Jasper Ridge Biological Preserve (JRBP), which includes part of the San Francisquito Creek riparian channel, the last channel of its kind between San Jose and San Francisco still in its natural state.

\subsection{Climate}

The climate in the SLAC area is Mediterranean. Winters are cool and moist, and summers are mostly warm and dry. Daily mean temperatures are seldom below 32 degrees Fahrenheit or above 86 degrees Fahrenheit. Rainfall averages about 22 inches per year. The distribution of precipitation is highly seasonal. About 75 percent of the precipitation, including most of the major storms, occurs during the four-month period from December through March. Most winter storm periods last from two days to a week in duration. The storm centers are usually characterized by relatively heavy rainfall and high winds.

\subsection{Land Use}

The SLAC site is located on an unincorporated portion of San Mateo County and is zoned in the San Mateo County General Plan as a residential estate. Approximately 27 percent of the property is developed with buildings and pavement, mostly in the core campus area.

Land use to the immediate west is commercial (office buildings and a hotel), and farther west is agricultural and the JRBP. Land use to the north is mostly commercial, residential, and recreational (a golf course), with a school and office buildings located north of the central campus. Land use to the east is residential, recreational (another golf course), and educational (the Stanford campus). Land use to the south is agricultural (including a horse boarding and training facility), preserved open space, and residential.

\subsection{Water Supply}

Domestic water for SLAC is supplied by the Menlo Park Municipal Water Department (MPMWD). The source is the City of San Francisco-operated Hetch Hetchy aqueduct system, which is fed from reservoirs located in the Sierra Nevada. SLAC, the neighboring Sharon Heights development (to the north), and the Stanford Shopping Center all receive water service from an independent system (called Zone 3) within the MPMWD. This separate system taps the Hetch Hetchy aqueduct and pumps water up to a 268,391-cubicfeet reservoir north of Sand Hill Road, approximately 1.5 miles from central SLAC.

Drinking and process water are transported throughout the SLAC site by a distribution system protected by backflow prevention devices. Use of water at SLAC is almost equally divided between equipment cooling (such as the linac) and domestic uses (such as landscape irrigation and drinking water). Groundwater is not 
used onsite at SLAC; however, five offsite groundwater wells have been identified within a one-mile radius of SLAC, three of which are in use. The closest downgradient groundwater well is located approximately 500 feet south of SLAC along the stream margin of San Francisquito Creek. This well was formerly used for agricultural supply but is now capped. Of the other four wells, one is capped, one is used for watering livestock, and the other two are used for residential drinking water.

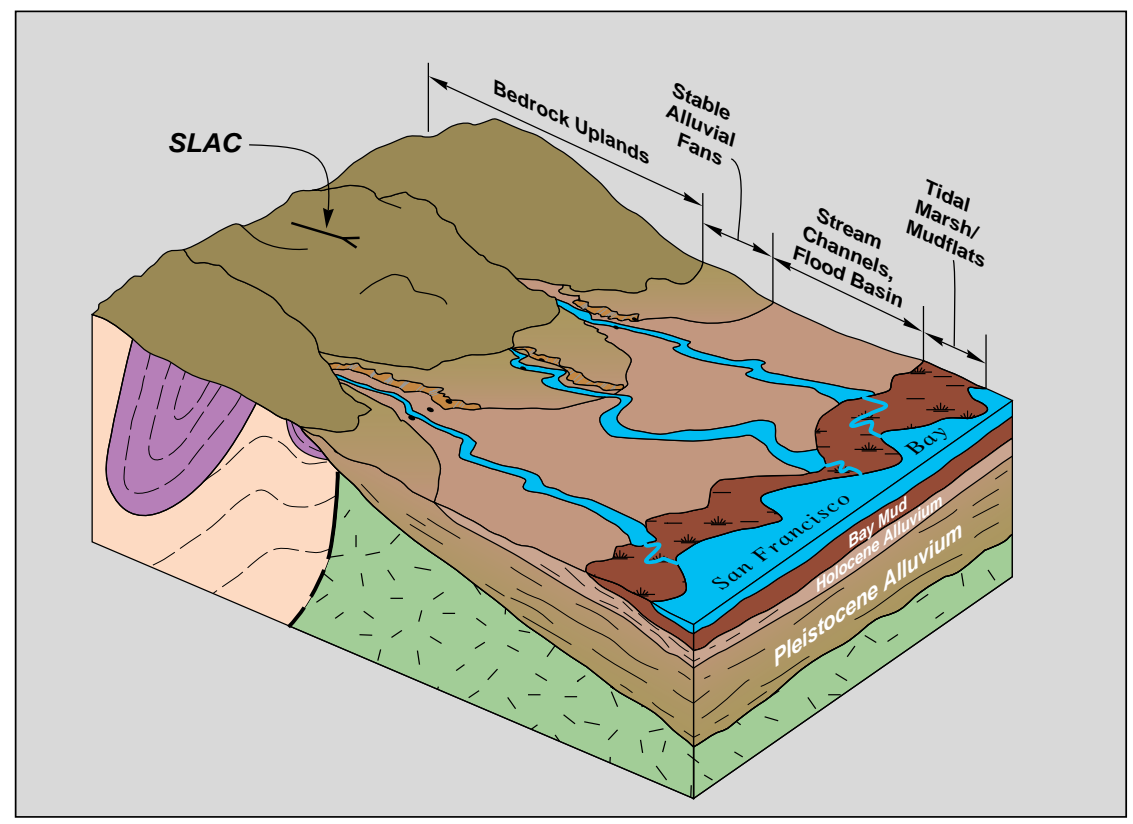

Figure 1-2 Site Area General Geographic and Geologic Setting

\subsection{Geology}

The SLAC site is underlain by sandstone, with some basalt at the far eastern end. In general, the bedrock on which the western half of the SLAC linac rests is the Whiskey Hill Formation (Eocene age), and the bedrock under the eastern half is the Ladera Sandstone (Miocene age). On top of this bedrock at various places along the accelerator alignment is the Santa Clara Formation (Pleistocene age), where alluvial deposits of sand and gravel are found. At the surface is a soil overburden of non-consolidated earth material ranging from 0.3 to 3 feet in depth. Figure 1-2 shows the general geographic and geologic setting of the area.

\subsection{Demographics}

SLAC's primary customers are the approximately 3,000 students, postdoctoral students, and visiting scientists from around the world who make use of its accelerator-based instrumentation and techniques for their research each year. SLAC has an employee population of about 1,630, about 20 percent of which are $\mathrm{PhD}$ physicists. Approximately 60 percent of the SLAC staff are professionals, including physicists, engineers, programmers, and other scientific-related personnel. The balance of the staff comprises support personnel, including technicians, crafts personnel, laboratory assistants, and administrative assistants. In addition to the regular population, at any given time SLAC hosts between 900 and 1,000 visiting scientists.

The populated area around SLAC is a mix of offices, schools, single-family housing, apartments, condominiums, and Stanford University. SLAC is surrounded by five communities: the city of Menlo Park; the towns of Atherton, Portola Valley, and Woodside; and the unincorporated community of Stanford 
University, which is located in Santa Clara County. Nearby unincorporated communities in San Mateo County include Ladera and two neighborhoods located in western Menlo Park. Within one mile of SLAC's perimeter are two public and two private schools with elementary and/or middle-school students. 


\section{Environmental Compliance}

\subsection{Introduction}

This chapter provides a summary of the regulatory framework within which the environmental programs of SLAC operate, and compliance with those regulations for 2012.

\subsection{Regulatory Framework}

The SLAC External Requirements Management Dataset cites the environmental protection and safety requirements and standards that are applicable to the Laboratory.

\subsection{Environmental Permits and Notifications}

The permits held by SLAC in 2012 are shown in Table 2-1 below.

Table 2-1 General Permits Held by SLAC

\begin{tabular}{lllr} 
Issuing Agency & Permit Type & Description & Number \\
\hline $\begin{array}{l}\text { Bay Area Air Quality } \\
\text { Management District }\end{array}$ & Air quality & $\begin{array}{l}\text { Synthetic Minor Operating Permit (SMOP), issued } \\
\text { per Title V of the Clean Air Act }\end{array}$ & 1 \\
& $\begin{array}{l}\text { Encompasses 42 permitted sources and 20 exempt } \\
\text { sources of air emissions (after initial permitting, } \\
\text { permitted sources integrated into SMOP) }\end{array}$ & 62 \\
\hline $\begin{array}{lll}\text { California Department of } \\
\text { Toxic Substances Control }\end{array}$ & $\begin{array}{l}\text { Hazardous waste } \\
\text { treatment }\end{array}$ & $\begin{array}{l}\text { Unit 1A - Building 025, permit by rule (PBR) for } \\
\text { cyanide treatment tanks }\end{array}$ & 1 \\
& $\begin{array}{l}\text { Unit 1B - Building 038, PBR for metal finishing } \\
\text { pretreatment facility }\end{array}$ & 1 \\
& $\begin{array}{l}\text { Unit 1C - Building 038, PBR for batch hazardous } \\
\text { waste treatment tank }\end{array}$ & 1 \\
\hline $\begin{array}{l}\text { South Bayside System } \\
\text { Authority and West Bay } \\
\text { Sanitary District }\end{array}$ & $\begin{array}{l}\text { Wastewater } \\
\text { discharge }\end{array}$ & Mandatory Wastewater Discharge Permit & 1 \\
\hline $\begin{array}{l}\text { Regional Water Quality } \\
\text { Control Board }\end{array}$ & Stormwater & Industrial activities stormwater general permit & 1 \\
\hline
\end{tabular}




\begin{tabular}{|c|c|c|c|}
\hline Issuing Agency & Permit Type & Description & Number \\
\hline San Mateo County /CUPA & CUPA programs & $\begin{array}{l}\text { Permit By Rule; Above Ground Tank/SPCC; HazMat } \\
\text { Storage > 32000gal, 224000lb, 112000cf; HazWaste } \\
\text { Generator 51-250 tons; CalARP }\end{array}$ & 1 \\
\hline $\begin{array}{l}\text { US Environmental } \\
\text { Protection Agency }\end{array}$ & Hazardous waste & 90-day hazardous waste generator & 1 \\
\hline \multicolumn{4}{|c|}{$\begin{array}{l}\text { Notes: } \\
\text { CalARP - California Accidental Release Program } \\
\text { CUPA - Certified Unified Program Agency } \\
\text { Haz/Mat - Hazardous Material } \\
\text { PBR - Permit-By-Rule } \\
\text { SPCC - Spill Prevention, Control and Countermea }\end{array}$} \\
\hline
\end{tabular}

\subsection{Environmental Incidents}

\subsubsection{Non-radiological Incidents}

SLAC was in compliance with all non-radiological requirements related to the environment throughout 2012. During 2012, SLAC reported one Category 1 and one Category 2 sanitary sewer overflow to the State Water Resources Control Board. The respective volumes of those overflows were approximately 25 and 10 gallons.

\subsubsection{Radiological Incidents}

In 2012, no radiological incidents occurred that increased radiation levels above natural background to the public or released radioactivity to the environment. As detailed in Chapter 5, "Environmental Radiological Program," SLAC was in compliance with all radiological requirements related to the environment and the public throughout 2012.

\subsection{Assessments, Inspections, and Quality Assurance}

The environmental programs at SLAC are subject to assessments, inspections, and quality assurance measures. Those conducted during 2012 are reported here.

\subsubsection{Assessments}

External assessments conducted by regulators occur periodically and include quarterly radiation monitoring of the SLAC perimeter by California Department of Health Services. However, monitoring results are not currently available to SLAC.

The San Mateo County Certified Unified Program Agency (CUPA) inspected SLAC from July 25 through July 27, 2012. The inspection included the following programs:

- Hazardous Materials Business Plan

- Above-Ground Storage Tank

- Hazardous Waste Generator

- $\quad$ Surface Water Discharges

- $\quad$ Tiered Permitting

- Waste Tires 
SLAC submitted a response to the CUPA inspection and all findings were addressed in a timely manner.

On February 16, 2012, the CUPA conducted an assessment of the California Accidental Release Program (CalARP) pursuant to renewing the Risk Management Plan (RMP), which is required every 5 years. The RMP was updated to reflect current conditions and revised per comments from the CUPA representative. The revised RMP was submitted in a timely manner.

\subsubsection{Inspections}

Periodic inspections of the environmental programs are performed at SLAC by environmental regulatory agencies. Table 2-2 lists the inspections conducted in 2012 by these agencies.

Table 2-2 Environmental Audits and Inspections

\begin{tabular}{lllr} 
Regulatory Agency & Inspection Title & Date & Violations \\
\hline South Bayside System Authority & Annual Compliance Inspection & June 6, 2012 & 0 \\
San Mateo County CUPA & Annual Compliance Inspection & July 25-27, 2012 & 0 \\
Regional Water Quality Control Board & Storm Water Inspection & September 11, 2012 & 0
\end{tabular}

\subsubsection{Quality Assurance}

The SLAC site-wide quality assurance (QA) program is consistent with the requirements of DOE Order 414.1D, ${ }^{2}$ and includes documented roles, responsibilities, and authorities for implementing the 10 criteria from the DOE order. Environmental Program Assessments of program elements are conducted by SLAC no less frequently than once every three years and are tracked in the Integrated Assessment Schedule (IAS), maintained by the SLAC Office of Assurance.

The SLAC Office of Assurance is responsible for:

- Auditing quality assurance for line work as well as Environment, Safety and Health (ES\&H) programs

- Maintaining the SLAC Institutional Quality Assurance Program Plan

- Providing direction for implementation of the ten criteria from DOE Order 414.1D

\subsubsection{Environmental Non-radiological Program}

The Environmental Restoration Program uses the Quality Assurance Project Plan for the Environmental Restoration Program ${ }^{3}$ for soil and groundwater characterization and remediation activities. This document includes all components required of quality assurance project plans and is consistent with United States Environmental Protection Agency (USEPA), Comprehensive Environmental Response, Compensation, and Liability Act (CERCLA, or Superfund), and DOE guidance documents. The components include defining

2 United States Department of Energy, DOE Order 414.1D, "Quality Assurance”, http://www.directives.doe.gov/pdfs/doe/doetext/neword/414/04141c.html

3 Stanford Linear Accelerator Center, Environment, Safety, and Health Division, Environmental Protection Department, Quality Assurance Project Plan for the Environmental Restoration Program (SLAC-I-750-2A17M-003 R004, November 2010) 
required laboratory and field QA and quality control (QC) procedures and corrective actions, along with data validation and reporting.

\subsubsection{Environmental Radiological Program}

Programmatic QA/QC is governed by the SLAC Radiological Environmental Protection (REP) program manual, and specific radioanalysis laboratory procedures and data validation and reporting are governed by the SLAC Radioanalysis Laboratory Quality Assurance Manual. In addition, twice per year, SLAC participates in the Mixed Analyte Performance Evaluation Program (MAPEP) administered by the DOE Idaho National Laboratory (INL). Under this program, the INL provided the SLAC Radioanalysis Laboratory with samples that contained unknown gamma- and beta-emitting radionuclides. SLAC used these samples to test and improve the performance of its gamma counting and liquid scintillation counting systems. This ensures that the lab's counting system performs accurate measurements. The technical performances of the MAPEP procedures in 2012 were all acceptable. 


\section{Management Systems}

\subsection{Introduction}

This chapter provides an overview of the SLAC organizational structure, management approach, and EMS implementation used to protect the environment. The results for the various measures and reviews discussed below are contained in Chapter 2, "Environmental Compliance".

\subsection{SLAC Organization}

During the calendar year of 2012 SLAC was organized into six directorates: Accelerator Directorate, Operations Directorate, Photon Science Directorate, Particle Physics and Astrophysics Directorate, SSRL Directorate and Linac Coherent Light Source Directorate. Additionally, the SLAC Office of Assurance, which was renamed the Office of Planning and Assessment (OPA), was formed in 2006 in response to DOE Order 226.1A, Implementation of Department of Energy Oversight Policy. DOE Oder 226.1A has since been replaced by SLAC's Contractor Assurance System. The purpose of SLAC's assurance program is to ensure that products and services meet or exceed customers' expectations. A reorganization of SLAC during 2013 combined the ES\&H Division with parts of the OPA, to form the new Environmental, Safety, Health and Quality Division. However, since the time period for this report is calendar year 2012, the term “ES\&H Division” will be used throughout this report. SLAC's customers include the DOE, the many users who participate in experiments at SLAC using the laboratory's unique experimental facilities, and the sponsors of work conducted under the work-for-others program.

\subsection{ES\&H Division Organization}

The ES\&H Division consists of six departments (see below) and a Division Office. The Division Office is tasked with overall strategic planning and management, along with work planning and control. The shared goal is to ensure that SLAC operates in compliance with federal, state, and local laws and regulations, as well as DOE directives.

\subsubsection{Environmental Protection Department}

The Environmental Protection (EP) Department has two technical groups (Environmental Protection Group and Environmental Restoration Group) that are responsible for developing and managing the requirements under the EMS. The EMS is the overarching management system that SLAC uses for identifying and managing environmental aspects and is further described in Section 3.5. The EP Group develops and implements the following programs: waste minimization and pollution prevention, stormwater and industrial wastewater, air, toxic substances control, spill prevention and groundwater protection. The Environmental Restoration Group oversees work to restore soil and groundwater impacted with chemicals from historical operations.

\subsubsection{Field Services Department}

The Field Services Department consists of four technical groups - Waste Management (WM) Group, Industrial Hygiene Group, Chemical Management Group and Field Safety Group. The Waste Management Group is responsible for coordinating the management and off-site disposal of regulated and hazardous wastes, and developing and implementing hazardous waste minimization plans. The Industrial Hygiene 
Group is responsible for assisting with the management of SLAC's safety and health programs, and keeping SLAC healthy and safe by anticipation, recognition, evaluation, prevention, and control of environmental factors or stresses which may cause sickness or impaired health and well being. The Chemical Management Group is multifaceted and addresses chemical safety at every point in the chemical lifecycle from transportation, procurement, use, storage, inventory management, and implements the Toxic and Hazardous Material Reduction Plan. The Field Safety Group is responsible for providing industrial and Occupational Safety and Health Administration (OSHA) construction safety oversight to construction projects, operations and maintenance, as well as providing safety training classes to SLAC personnel.

\subsubsection{Security and Emergency Management Department}

The SLAC Fire Marshal's Office works with SLAC Security to provide oversight of two intertwined site safety functions -- Fire Protection and Emergency Response. Fire protection is led by the SLAC Fire Marshal. Fire protection program oversight is provided by two licensed fire protection engineers in conjunction with several fire protection specialists. Emergency response oversight is led by the Assistant Fire Marshal, who is also SLAC's Emergency Management Coordinator. The SLAC internal emergency management organization includes the SLAC Emergency Response Team (ERT) and SLAC Site Security. The Fire Marshal's Office includes a full-time Emergency Response Specialist in addition to the Emergency Management Coordinator. In 2012, emergency response was supported by personnel under contract from the Palo Alto Fire Department (PAFD) through the end of April. PAFD staffed Station 7 which was located on-site and provided firefighter/medic emergency response services 24 hours-a-day, seven days-a-week. As of May 1, 2012, SLAC has been supported by the County of San Mateo through a Memorandum of Agreement with the Menlo Park Fire Protection District. Site Security is led by a SLAC Security Manager and staffed by contract security professionals who are responsible for providing security services and emergency assistance 24 hours a day, seven days a week.

\subsubsection{Radiation Protection Department}

The SLAC Radiation Protection (RP) Department includes five technical groups - The Radiation Physics Group, Radiation Protection Field Operations Group (RPFO), Dosimetry and Radiological Environmental Protection Group, Radioactive Waste Management Group, and Laser Safety Group. The Radiation Physics Group is responsible for providing expertise in safety analysis and control (including shielding calculations and safety system design) for new or modified beam lines, experiments and facilities, and providing authorization and oversight for the safe operation of beam lines and experiments to protect the workers, the general public and the environment. The RPFO Group is responsible for overseeing radiological monitoring, training, radiological control and work support. The Dosimetry and Radiological Environmental Protection Group is responsible for providing dosimetry services (external, internal and area), assessment and/or monitoring of various types of environmental impact (described in more details in Section 5), operation of the Radioanalysis Laboratory, and operation of instrumentation program. The Radioactive Waste Management Group is responsible for overseeing radioactive waste management at SLAC, such as low level radioactive waste disposal (described in more details in Chapter 5). The Laser Safety Group is responsible for developing and implementing SLAC’s Laser Safety Program.

\subsubsection{Project Safety Department}

The ES\&H Project Safety Department consists of three groups - the Building Inspection Office, Project Safety Support Group, and Safety Officer Group. The Building Inspection Office is responsible for providing Building Code oversight of construction projects during the plan review process and construction phases. The Project Safety Support Group is responsible for general construction safety oversight, subcontractor safety (occupational safety and health metrics) evaluation, project support (ES\&H liaison) to project managers and scientists, and safety oversight of specific programs in areas such as oxygen deficiency hazards, and compressed gas systems. The Safety Officer Group consists of the SLAC Fire Marshal and the Electrical Safety Officer. 


\subsubsection{Training and Information Management Department}

The Training and Information Management Department assists with the implementation of SLAC's safety and health programs including ES\&H training, ES\&H publishing, and ES\&H web and business applications.

\subsection{Integrated Safety and Environmental Management System}

SLAC ensures that the site is operated in a safe, environmentally responsible manner and complies with applicable laws, regulations, standards and other requirements through implementation of an Integrated Safety and Environmental Management System (ISEMS). The ISEMS integrates the key elements of effective safety and environmental management systems into the mission and everyday operations of the site.

\subsubsection{Integrated Safety and Environmental Management System}

The 'plan, do, check, and improve' approach of ISEMS ${ }^{4}$ has been formally adopted by SLAC, and has been incorporated into the Worker Safety and Health Plan. ${ }^{5}$ Work at SLAC follows the five core functions of Integrated Safety Management (ISM), which is consistent with the EMS process (policy, planning, implementation, checking and corrective action, and management review):

- Define the scope of work

- Analyze the hazards

- Develop and implement hazard controls

- Perform work within controls

- Provide feedback and continuous improvement

\subsubsection{Requirements Management System}

The laws and regulations that specify the ES\&H and other external requirements of the Laboratory are cited in the centralized SLAC External Requirements dataset which is maintained by the SLAC Contract Management Group. Updates to the external requirements dataset occur: when the DOE/Stanford University contract for SLAC is modified, affecting changes to clauses or DOE Directives; when Management System documentation (e.g., the ES\&H Manual) is revised; and when other non-contractual external requirements (e.g., industrial safety standards) are identified based on subject matter expert (SME) input. In addition, SMEs review the dataset at least annually to ensure that regulatory drivers are identified and incorporated.

\subsubsection{Environmental Performance Measures}

In addition to complying with external requirements, SLAC evaluates its performance against measures and metrics. Specific performance objectives, measures and targets are developed by DOE and SLAC, and are approved and formally incorporated into the $\mathrm{M} \& \mathrm{O}$ contract each fiscal year. DOE uses the contract

$4 \quad$ Stanford Linear Accelerator Center, Environment, Safety, and Health Division, “Integrated Safety and Environmental Management Systems”, http://www-group.slac.stanford.edu/esh/general/isems/

5 SLAC National Accelerator Laboratory, Environment, Safety, and Health Division, SLAC Worker Safety and Health Program, (SLAC-I-720-)A21B-001-R004), http://www-Worker Safety and Health Program (WSHP) 
performance measures and ongoing field observations of SLAC operations and construction activities to formally evaluate contractor performance in all areas, including ES\&H.

In fiscal year (FY) 2012, SLAC established environmentally relevant performance goals to ensure protection of the environment. Measures were taken to ensure the effective development, implementation, and maintenance of an efficient Environmental Management System.

SLAC received a grade of A for its environmental performance. In particular, the following accomplishments were made in FY 2012:

- $\quad$ SLAC recycled over 100 tons of scrap metal from BaBar and PEP-II dismantling activities.

- SLAC completed the NEPA EA for the LCLS-II project, a key milestone for DOE approval of the Critical Decision-2 (CD-2) for the project.

- $\quad$ SLAC completed the NHPA Section 106 consultation process with the SHPO for the Sector 10 LCLS-II X-ray laser injector support alcove, demolition of the cafeteria (Building 42) and the auditorium (Building 43) for construction of the SUSB, and renovation of the Administration and Engineering building (Building 41).

- SLAC has made significant progress in the cleanup of legacy contamination of groundwater, by reducing the area of concern by over 80 percent in four areas and VOC concentrations by over 99 percent in two areas.

\subsubsection{Training}

To ensure every employee is both aware and capable of fulfilling his or her responsibilities, the ES\&H Division operates an extensive program of classroom and computer-based training. For example, personnel who handle hazardous chemicals and waste are provided training in chemical and waste management, waste minimization, pollution prevention, stormwater protection, on-site transportation of hazardous chemicals and waste, and basic spill and emergency response. Details on the ES\&H training program are available online. ${ }^{6}$ Workers are required to have all appropriate environmental and safety training prior to performing any work assigned to them. Training received by each worker is documented in his or her Safety Training Assessment, which is reviewed and approved annually by their supervisor.

\subsection{Environmental Management System}

The EMS portion of the ISEMS is essentially a systematic approach for ensuring environmental improvement - a continual cycle of planning, implementing, reviewing and improving to ensure protection of the air, water, land, and other natural resources that may be potentially impacted by operational activities. SLAC's EMS program is described in detail in the EMS Description ${ }^{7}$ document.

The Office of Management and Budget issues an annual Environmental Stewardship scorecard for the federal agencies and an EMS Report Card is one of four elements. SLAC achieved a score of "green" on its 2012 EMS Report Card, indicating that all elements of the EMS are in place and working. Despite receiving a score of "green", SLAC strives to continually improve its EMS.

6 Stanford Linear Accelerator Center, Environment, Safety, and Health Division, Training, http://wwwgroup.slac.stanford.edu/esh/training/

7 SLAC National Accelerator Laboratory, EMS Description, SLAC-750-0A03H-002 R4, September 2012 
SLAC's EMS program is consistent with International Organization of Standardization (ISO) 14001:2004. It was first formally in place on December 21, 2005, following a DOE assessment, and has been assessed and revalidated every three years since that time. SLAC's EMS was last assessed in April 2012 by the DOE who determined the EMS to be fully implemented and in conformance with ISO 14001:2004. Based on these results, SLAC's EMS was revalidated by the DOE in June 2012.

The annual review and update of environmental aspects and determination of significance was completed this year by SLAC's EMS Steering Committee and Environmental Safety Committee (ESC), and nine objectives and targets were established for 2012. For each objective and target, a work plan, termed an Environmental Management Program, was completed. Six of the nine EMPs were completed in FY 2012, with three continuing into FY 2013.

Objectives and targets were developed for the following environmental aspects in FY 2012:

- Chemical use, storage, and inventory

- Industrial and hazardous waste generation

- Surface water and stormwater

- Use, reuse, and recycling

- Conservation of resources

- Cultural/historical resource disturbance and interaction with wildlife/habitat

Notable accomplishments for the 2012 EMPs include the following:

- The number of items in SLAC's Greener Choices catalog for chemical purchases was expanded by 15 percent in FY 2012. The Greener Choices catalog was added to SLAC's online chemical management system several years ago to aid chemical purchasers in finding less toxic alternatives.

- A zero-waste pilot program was implemented at one of SLAC's newly renovated office buildings where it is estimated that over 75 percent of the buildings waste is being diverted from the landfill through recycling and composting food waste and paper towels. Based on the success of the pilot program, the program was expanded to an additional existing office building in FY 2012.

- To enhance SLAC's existing recycling program, recycling bin signage was redesigned using a new color-coded system and deployed at 500-plus recycling collection bins.

- SLAC switched all of its electronics recycling to certified recyclers, helping to ensure sound endof-life management of electronics. Previously, certified recyclers were used only for cathode ray tube (CRT) devices.

- SLAC completed a boiler replacement and upgrade. One new boiler with low nitrogen oxides burners was added and a second boiler was re-tubed with a new low nitrogen oxides burner, resulting in 2,600 one-thousand British Thermal Units of Heat (MBTUH) resulting in $\$ 10,000$ energy savings, and reduced maintenance requirements.

- $\quad$ Phase Three of a five-phase project for installation of advanced metering was completed. Approximately 25 meters were installed onto the Schneider ION System, resulting in the estimated savings of approximately 2.5 percent for the 13 buildings that received them, based on improved awareness.

- Energy-efficient lighting upgrades were completed in buildings 035, 050, and 082, resulting in savings of 274,000 kilowatt ( $\mathrm{kW}$ ) hours and \$32,000 in operation and maintenance costs. 
Additionally, SLAC's progress on the sustainability goals of EO 13423 and EO 13514, including greenhouse gases (GHG), energy, water, fuel-reduction and high-performance sustainable buildings is provided in Section 4.7, Sustainability. SLAC's GHG inventory work is also discussed in Section 4.2.2.9. 


\section{Environmental Non-radiological Programs}

\subsection{Introduction}

During the course of providing accelerators, detectors, instrumentation, and support for national and international research programs, SLAC manufactures and maintains one-of-a-kind research equipment, which requires the use and management of various industrial chemicals, gases and metals. In addition, SLAC has the potential to impact the environment due to storage and handling of chemicals and the large quantities of electricity and cooling water that are used in the operation of the accelerator. Finally, SLAC has environmental management issues typical of any employer with more than 1,630 full-time staff, 3,000 scientific users per year, hundreds of buildings, and 426 acres of land, some of which are adjacent to a biological preserve.

SLAC has focused considerable efforts to minimize potential environmental impacts. SLAC works to eliminate generations of waste and emissions. When unavoidable, SLAC attempts to minimize the amount it does produce and then carefully manages the environmental impacts that may occur. Additionally, SLAC continually strives to improve its environmental performance.

Recognition of SLAC’s environmental performance accomplishments is provided in Table 4-1.

Table 4-1 Recent Environmental Awards

\begin{tabular}{llll} 
Year & Organization & Award/Recognition Program & Description \\
\hline 2008 & USEPA & $\begin{array}{l}\text { Federal Electronics Challenge - Bronze } \\
\text { Award }\end{array}$ & $\begin{array}{l}\text { Reducing the environmental impacts of } \\
\text { electronics in the purchasing life-cycle } \\
\text { phase }\end{array}$ \\
2009 & USEPA & $\begin{array}{l}\text { Federal Electronics Challenge - Bronze } \\
\text { Award }\end{array}$ & $\begin{array}{l}\text { Reducing the environmental impacts of } \\
\text { electronics in the purchasing life-cycle } \\
\text { phase }\end{array}$ \\
2011 & DOE & Secretarial Honors Achievement Award & $\begin{array}{l}\text { Reducing fugitive emissions of sulfur } \\
\text { hexafluoride (SF6) while raising awareness } \\
\text { and sharing case studies }\end{array}$
\end{tabular}

This chapter provides an overview of the non-radiological environmental programs SLAC implements to protect air and water quality, to manage hazardous materials in a safe and environmentally responsible manner, and to eliminate or minimize the generation of hazardous, non-hazardous, and solid waste. The chapter sections are organized by environmental protection program and describe the regulatory framework, program status for 2012, and relevant performance trends. The environmental radiological program is discussed in Chapter 5 , and programs covering the monitoring and remediation of groundwater, soil, and sediment are discussed in Chapter 6.

\subsection{Air Quality Management Programs}

SLAC operates various sources that emit air pollutants, including a plating shop, a paint shop, several machine shops, boilers, solvent degreasers, emergency generators, and a vehicle fueling station. In addition, greenhouse gases (GHGs) which are used extensively in both electrical substations and research equipment, are being actively managed per Assembly Bill (AB) 32, the California Global Warming Solutions Act, in 2006. This section describes the regulatory framework to which SLAC is subject for the purpose of air quality protection, and presents the status of SLAC's air quality protection programs during 2012. 


\subsubsection{Regulatory Framework}

In the San Francisco Bay Area, most federal and state air regulatory programs are implemented through the rules and regulations of the Bay Area Air Quality Management District (BAAQMD). Included in the BAAQMD roles and responsibilities is the implementation of Title V of the Clean Air Act. SLAC's Title V Synthetic Minor Operating Permit (SMOP) was issued by BAAQMD on July 26, 2002. The SMOP stipulates limits on facility-wide emissions of VOCs, total hazardous air pollutants (HAPs), and individual HAPs, along with various other requirements. At the state level, the California Air Resources Board (CARB) is responsible for administering AB 32, the implementation of which was completed in 2012, and providing notices, workshops, training, lectures, and other means to disseminate information as it is developed.

Finally, SLAC is subject to the following two federal air quality programs, both of which are administered through the Air Division of USEPA Region 9:

- National Emission Standards for Halogenated Solvent Cleaning, under Title 40, Code of Federal Regulations (CFR), Part 63.460

- $\quad$ Protection of Stratospheric Ozone, under 40 CFR 82

\subsubsection{Program Status}

\subsubsection{Biennial Facility Enforcement Inspection}

The most recent biennial BAAQMD inspection occurred in 2011, so no inspection was performed in 2012.

\subsubsection{New Source Permits}

Four new emissions sources were permitted and an existing source was modified during 2012:

- A $175 \mathrm{~kW}$ emergency generator was installed at the new Research Support Building

- A $50 \mathrm{~kW}$ emergency generator was installed next to Building 706 to replace an older unit.

- A new solvent cleaner that uses an alternative was installed in the Plating Shop An existing boiler was upgraded with a more efficient burner assembly and improved controls

Of the two main boilers in the Central Utilities Building, one was replaced with a new unit and the other was upgraded with a new burner and control system. In addition, a permitted solvent-cleaning operation in the Cryogenics Building was terminated. Finally, a permit-exempt operation, a plasma-arc cutting torch, was decommissioned. At the end of 2012, SLAC managed a total of 62 sources of air emissions, comprising 42 permitted sources and 20 exempt sources.

\subsubsection{Annual Update for Permit-to-Operate and Annual Title V SMOP Emissions Report}

SLAC has two overarching annual deliverables to BAAQMD as well as others described in subsequent sections. One primary deliverable submitted was the annual information update requested by BAAQMD for selected permitted sources, covering calendar year (CY) 2011. This report was submitted on time in April 2012, and SLAC's permit-to-operate was renewed on June 27, 2012 and is effective through June 30, 2013.

The other overarching BAAQMD deliverable was the Title $\mathrm{V}$ annual emissions report for all onsite sources included in the SMOP, covering the period of July 1, 2011, through June 30, 2012. SLAC submitted the Title V annual emissions report on time in July 2012.

\subsubsection{Annual Adhesives Usage Report}

SLAC submitted its annual adhesives usage report to BAAQMD to satisfy Regulation 8-51-502.2c on time in April 2012 (covering the 2011 reporting year). 


\subsubsection{Annual Air Toxics Report}

SLAC submitted its annual air toxics report to BAAQMD in accordance with AB2588 on time in April 2012.

\subsubsection{Asbestos and Demolition Project Notification Program}

For projects that involve the demolition or significant renovation of existing structures, or the management of regulated asbestos-containing material, SLAC is required to provide advance notice to BAAQMD. During 2012, 17 construction projects were evaluated for the purpose of air quality protection. Based on the project scopes and the results of pre-work asbestos surveys, asbestos/demolition/renovation notifications were submitted to BAAQMD for six of these projects.

\subsubsection{National Emission Standards for Hazardous Air Pollutants}

During 2012, SLAC owned three emissions sources that are subject to 40 CFR 63, Subpart T "National Emission Standards for Halogenated Solvent Cleaning" which is part of the National Emission Standards for Hazardous Air Pollutants (NESHAP) regulations. Of the three regulated units (solvent cleaners and degreasers), only one was in service during 2012. This unit, a vapor degreaser in the Plating Shop, was operated in accordance with the applicable NESHAP emissions limits, and there were no exceedances of regulatory limits. The NESHAP deliverables required by USEPA are an annual performance report and two semi-annual exceedance reports. For CY 2011, the annual report is consolidated with the second semiannual report, and was submitted on time in January 2012. The first semi-annual report for CY 2012 was submitted on time in July 2012.

\subsubsection{Vehicle Fleet Management and Source Testing}

SLAC operates, fuels, and maintains a diverse fleet of cars, trucks, and specialized pieces of heavy equipment to support its daily operations. Vehicles are provided by one of two federal agencies: the DOE or the United States General Services Administration. SLAC continues to replace and upgrade its service fleet as resources allow.

To reduce the amount of petroleum-based fuel used at SLAC, in accordance with EO 13423 and EO 13514, in 2010 SLAC Fleet Services converted the diesel pumping system at the gasoline dispensing facility (GDF) to dispense an ethanol blend (E85). In addition, diesel fuel is now pumped directly into portable trailer-mounted tanks, which are then transported throughout the facility to refuel heavy equipment and stationary engines, such as emergency generators.

Fuel purchasing and dispensing is tracked and reported annually to BAAQMD. The permit for the GDF requires annual source testing of the gasoline dispensing system to ensure proper functioning. A source test was performed on the GDF in September 2012, and all results were within regulatory limits.

\subsubsection{Greenhouse Gas Inventory and Baseline}

GHG emissions are divided into 3 categories, or scopes. Scope 1 emissions are generated onsite and are under the direct control of the facility, such as those from natural gas that is combusted in a boiler. Scope 2 emissions occurs onsite, but they are not generated by the facility, such as electrical power purchased from an offsite entity. Nearly all of SLAC's GHG emissions are Scope 2, due to its high demand for electricity. Scope 3 emissions are business-related but generated offsite; employee commuting and business travel fall into this category. SLAC deployed its first annual commuter survey in 2012 to get a sense of how people commute to and from work, and investigate the feasibility of various commuting alternatives. Sixteen percent of the target audience completed the survey. The response is expected to improve in future years through greater outreach.

The DOE, in conformance with EO 13514 requirements, began establishing an agency-wide GHG baseline of its Scope 1 and 2 emissions in FY 2008, using energy and fuel data collected in existing DOE reporting 
systems. Fugitive emissions data were calculated based on site chemical purchasing data. In December 2012, SLAC submitted its Comprehensive Energy Data Report to DOE, which provided an initial estimate of Scope 3 emissions as well.

As part of its GHG management program, CARB established a program that specifically addresses electrical equipment filled with sulfur hexafluoride $\left(\mathrm{SF}_{6}\right)$. This compound is the most powerful GHG known, having a Global Warming Potential (GWP) of 23,900 relative to carbon dioxide $\left(\mathrm{CO}_{2}\right)$, which has a GWP of 1 . The first $\mathrm{SF}_{6}$ inventory report was submitted online before the June 1, 2012 deadline.

\subsection{Industrial and Sanitary Wastewater Management Program}

SLAC discharges industrial wastewater and sanitary sewage to the sewage collection system operated by the West Bay Sanitary District (WBSD). The sewage is then conveyed via the WBSD's collection system to the wastewater treatment plant operated by the South Bayside System Authority (SBSA). This section describes the regulatory framework under which SLAC operates for the purpose of water quality protection, and presents the status of SLAC's water quality protection programs in 2012.

\subsubsection{Regulatory Framework}

The Federal Water Pollution Control Act, now referred to as the Clean Water Act (CWA), was enacted in 1972 to halt the degradation of our nation's waters. The CWA established the National Pollutant Discharge Elimination System, which regulates discharges of wastewater from point sources such as a publicly owned treatment work and categorically regulated industrial facilities such as electroplating shops. In 1987, the CWA was amended to include non-point source discharges such as stormwater run-off from industrial, municipal, and construction activities. The CWA is the primary driver behind the SLAC water quality protection programs.

SLAC operates its industrial and sanitary wastewater programs under mandatory wastewater discharge permits which are negotiated jointly with the WBSD and SBSA. The previous permit, which covered the entire facility, was effective from December 16, 2006 to December 15, 2011. A new permit became effective December 16, 2011 and may be renewed annually until December 15, 2016. SLAC also has a contractual relationship with the WBSD, which specifies the total industrial and sanitary flow that is allowed to be discharged.

SLAC's industrial and sanitary monitoring locations are shown in Figure 4-1. SLAC's Sand Hill Road flow metering station (Sand Hill flow meter station [(FMS)]) is located immediately upstream of SLAC's sewer system connection to WBSD's Sand Hill Road trunk line, just to the north of the SLAC main gate.

SLAC also has four flow monitoring stations on the south side of the facility, which collectively monitor the flow SLAC discharges to the WBSD’s Alpine Road trunk line. The four locations are Master Substation (MSub), Alpine Gate (Alpine), Former Hazardous Waste Storage Area (FHWSA) Treatment System and Interaction Region 8 (IR08), as shown on Figure 4-1. 


\section{Industrial and Sanitary Water Monitoring Locations}

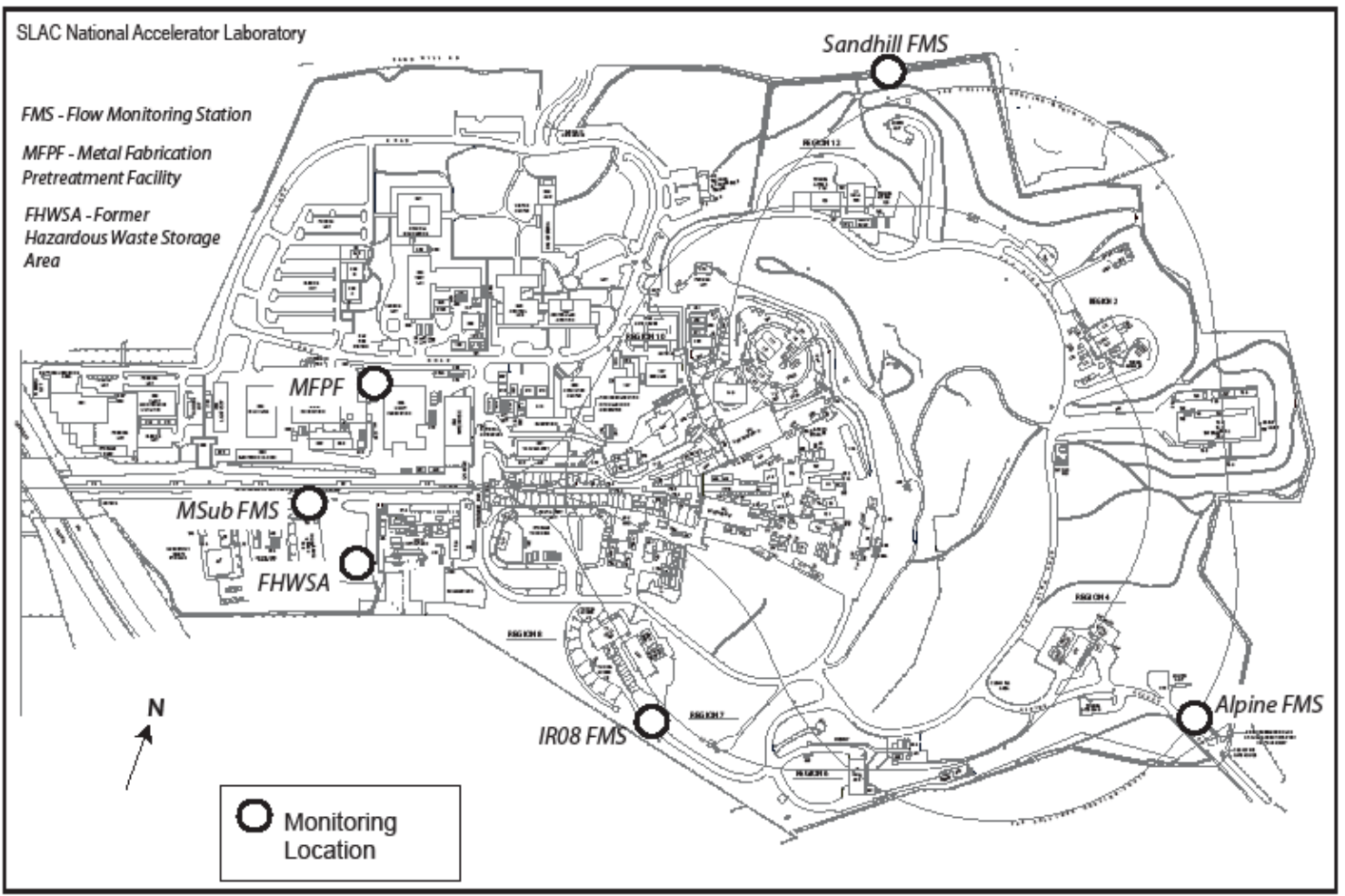

Figure 4-1 Industrial and Sanitary Wastewater Monitoring Locations

SLAC is required to submit a semi-annual self-monitoring report ${ }^{8}$ which includes the results of its monitoring of the metal finishing pre-treatment facility (MFPF) and FHWSA Treatment System, certification of a solvent management plan for approximately 100 solvents selected by the SBSA, and reports for discharges of radioactivity in industrial wastewater (see Section 5.5.1).

\subsubsection{Program Status}

\subsubsection{Annual Facility Enforcement Inspection}

The SBSA conducted the annual facility enforcement inspection on June 6, 2012. No issues were noted.

\subsubsection{Water Quality Monitoring Results}

SLAC collects water quality samples semi-annually from the MFPF and FHWSA monitoring locations. In addition, SBSA collects samples quarterly at the Sand Hill Road FMS and annually at both the MFPF and FHWSA. Compliance with the water quality parameters contained in the permit is determined at the Sand Hill Road FMS and FHWSA by comparing the mass discharge limit with the average value of the samples

8 SLAC National Accelerator Laboratory, Environment, Safety, and Health Division, Environmental Protection Department, Self-Monitoring Report and SMP Certification Required Under Mandatory Wastewater Discharge Permit WB 111216 (July 27, 2012, submitted to Norman Domingo, Technical Services Supervisor, SBSA)

SLAC National Accelerator Laboratory, Self-Monitoring Report and SMP Certification Required Under Mandatory Wastewater Discharge Permit WB 111216 (January 25, 2013, submitted to Norman Domingo, Technical Services Supervisor, SBSA) 
taken over the previous 12 months. SLAC was in compliance with all permitted discharge limits at all three monitoring locations in 2012. The higher than usual nickel concentration was due to a larger than normal discharge volume on the date sampled, however, SLAC was still in compliance with discharge requirements.

\subsubsection{Sanitary Sewer Overflow Management}

SLAC filed a Notice of Intent with the State Water Resources Control Board (SWRCB) to comply with the terms of the Statewide General Waste Discharge Requirements for Sanitary Sewer Systems. ${ }^{9}$ In August of 2010, the SLAC Sanitary Sewer Management Plan (SSMP) was completed and certified. The Plan includes descriptions of SLAC's sanitary sewer operations and maintenance activities, spill response, and reporting procedures. The SSMP was updated in 2013 based on the findings of the internal biennial audit that was conducted in August 2012.

SLAC registered with the SWRCB and the San Francisco Bay RWQCB sanitary sewer overflow reporting systems in October 2008. All spills from the sanitary sewer system are reported using the sanitary sewer overflow reporting systems. A Category 1 sanitary sewer overflow is any spill from the sanitary sewer which enters a storm drain channel and is not recovered from the storm drain system, or is greater than 1,000 gallons. Category 1 spills must be reported within two hours of discovery if they are not recoverable from the storm drain system or within 3 days if they are greater than 1,000 gallons but do not enter or are recovered from the storm drain system. A Category 2 sanitary sewer overflow is any spill which is not Category 1. Category 2 overflows are reported within 30 days after the end of the month in which the overflow occurred. A no-spill certification must be completed within 30 days of a month in which no spills occur.

In 2012, SLAC reported one Category 1 spill of approximately 25 gallons and one Category 2 overflow of approximately 10 gallons.

\subsection{Surface Water Management Program}

Stormwater flows from the 426-acre SLAC site through 25 drainage channels. In certain areas of the site, stormwater has the potential to come into contact with industrial activities or facilities. Such activities or facilities include metal working, outdoor storage, cooling towers, electrical equipment operation, and secondary containments. Many of the channels drain areas where the stormwater has little or no potential of exposure to industrial activities. SLAC has identified eight monitoring locations which are representative of stormwater discharges associated with industrial activities. These are listed below and shown in Figure 4-2.

- Interaction Region 8 (IR-8) Channel

- IR-6 Channel (IR-6)

- $\quad$ North Adit Channel (NA)

- Main Gate East Channel (MGE)

- $\quad$ IR-2 North Channel (IR-2)

- Building 81 North Channel (B81)

- Building 15 (B15)

- $\quad$ Building 18 (B18)

${ }^{9}$ Statewide General WDRs for Sanitary Sewer Systems, WQO No. 2006-0003. Available at $\underline{\text { State Water }}$ Resources Control Board 


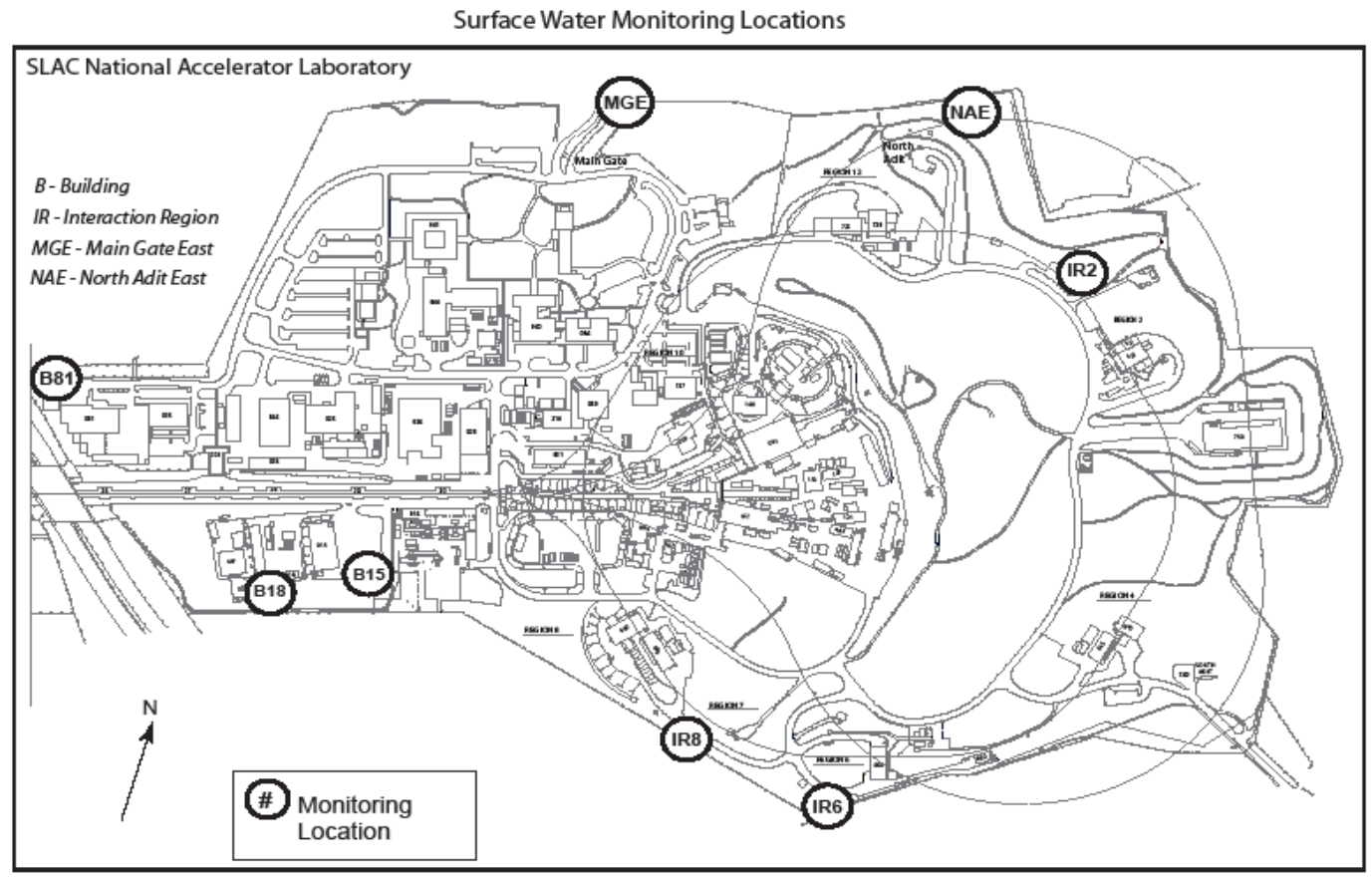

Figure 4-2 Surface Water Monitoring Locations

\subsubsection{Regulatory Framework}

Federal regulations allow authorized states to issue general permits to regulate industrial stormwater or non-point source discharges. California is an authorized state; and in 1991, the SWRCB adopted the industrial activities stormwater general permit, with the goal of reducing water pollution by regulating stormwater discharges associated with industrial activities. SLAC filed a notice of intent to comply with the general permit.

California's general permit was re-issued in 1997. SLAC adheres to the requirements of the general permit, through its development and implementation of a stormwater pollution prevention plan (SWPPP). ${ }^{10}$ The SWPPP has two main components: a stormwater monitoring program (SWMP) and a best management practice (BMP) program. ${ }^{11}$ The SWMP describes the rationale for sampling, lists the sampling locations, and specifies the analyses to be performed. The BMPs include a list of 17 generic and site-specific practices that serve to minimize the impact on stormwater from SLAC's industrial activities (see Section 4.4.2).

\subsubsection{Program Status}

SLAC's SWMP incorporates all general permit sampling and analysis requirements, such as frequency (samples collected from two eligible storms of the season), locations (samples collected from locations

10 Stanford Linear Accelerator Center, Environment, Safety, and Health Division, Environmental Protection and Restoration Department, SLAC Stormwater Pollution Prevention Plan (November 2007, SLAC-I-750-0A16M-002-R002)

11 Stanford Linear Accelerator Center, Environment, Safety, and Health Division, Environmental Protection Department, Stormwater, http://wwwgroup.slac.stanford.edu/esh/groups/ep/water/stormwater/ 
where stormwater comes into contact with industrial activities), analytes (SLAC analyzes for five metals and six non-metal analytes), and sampling methodologies.

The general permit's definition of wet season runs from October 1 through May 31. This reflects SLAC's climatological conditions, as rain rarely falls during June through September. Since the general permit's definition of wet season spans two calendar years, the 2012 water quality monitoring results discussed below are for the 2012-2013 wet season (October 2012 through May 2013).

The general permit requires submission of an annual report on stormwater activities by July 1 of each year, following the May 31 close of the wet season. ${ }^{12}$ SLAC met all sampling and analysis requirements in its SWMP and delivered its annual report, which included all water quality monitoring results, to the RWQCB.

Automated samplers are located at each of the stormwater monitoring sites. The samplers are triggered by rain gauges and level sensors. Samples are collected during the first eligible storm event at each location and one other event during the rainy season. During the wet season of 2012-2013, a total of 16 samples (two samples per location) were collected during six storm events.

The general permit requires analysis of stormwater samples for four parameters $(\mathrm{pH}$, total suspended solids, specific conductance, and total organic carbon), and any other potential pollutants, identified by the facility, which may be present in the stormwater in significant quantities. During the wet season of 2012-2013, stormwater samples were analyzed for the four required parameters as well as seven additional parameters (Table 4-2). The additional parameters were selected after a review of SLAC's industrial activities and the results of previous sampling events.

SLAC reviews and compares the analytical results with previous sampling data, background levels, and the SWRCB-developed parameter benchmark values (PBVs). ${ }^{13}$ PBVs are not regulatory discharge limits; rather, they are meant to be used as guidance. The majority of the sample results from the wet season of 2012-2013 were below PBVs. At several of the discharge locations, aluminum, iron, and zinc were present at levels above PBVs. Aluminum and iron concentrations reflect background levels of sediment entrained in the stormwater. The source of zinc is thought to be from contact with galvanized metal in stormwater drain pipes and metal roofs and drainpipes. SLAC will continue to evaluate sources of aluminum, iron and zinc in stormwater during future sampling events in order to determine how to reduce parameter benchmark value (PBV) exceedances that may be from industrial activities.

Table 4-2 Stormwater Parameters Analyzed

\begin{tabular}{|l|l|}
\hline Metals & Non-Metals \\
\hline Aluminum & Total Suspended Solids * \\
\hline Copper & Total Organic Carbon * \\
\hline Iron & $\mathrm{pH}^{*}$ \\
\hline Lead & Specific Conductance * \\
\hline Zinc & Polychlorinated Biphenyls \\
\hline & Radioactivity \\
\hline
\end{tabular}

* - Required parameter under Industrial Stormwater General Industrial Permit Order 97-03-DWQ

12 SLAC National Accelerator Laboratory, Environment, Safety, and Health Division, Environmental Protection Department, 2012-2013 Annual Report for Stormwater Discharges Associated with Industrial Activities (June 2013), San Francisco Bay RWQCB

${ }^{13}$ State of California, State Water Resources Control Board, Sampling and Analysis Reduction Certification (no date), http://www.waterboards.ca.gov/water_issues/programs/stormwater/docs/smanlrdc.pdf 


\subsection{Hazardous Materials Management}

SLAC uses hazardous materials as part of its experimental programs including the manufacturing and maintenance of experimental devices; as well as in conventional facilities operations, maintenance and construction projects. Examples of hazardous materials managed at SLAC include the following:

- Cryogens

- Compressed gases

- Acids and bases

- Solvents

- Oils and Fuels, including Propane

- Adhesives

- Paints and epoxies

- Metals

Hazardous materials management spans numerous programs but the purpose remains the same: to ensure the safe handling of hazardous materials in order to protect the workers, community, and environment.

\subsubsection{Regulatory Framework}

The regulatory framework for hazardous materials regulations, especially in California, has historically been a complex and overlapping web of statutes and regulations. Some of the most important regulatory drivers at the federal level include: Superfund Amendments and Reauthorization Act of 1986 (SARA) Title III), also referred to as the Emergency Planning and Community Right-to-Know Act (EPCRA), which focuses on community safety; the Occupational Safety and Health Act (1970), which addresses worker safety; the Hazardous Materials Transportation Act, whose purpose is to ensure the safe transport of hazardous materials in commerce; and the Toxic Substances Control Act (TSCA), the federal statute under which polychlorinated biphenyls (PCBs) and asbestos are regulated.

Important drivers at the state level generally date back to the mid-1980s and include a hazardous materials business plans (HMBP), the CalARP), the underground and aboveground storage tank programs, and pollution prevention and waste minimization programs.

In general, the local implementing agency for hazardous materials regulation in California is the CUPA. The Environmental Health Division of the San Mateo County Health Services Agency is the CUPA responsible for overseeing hazardous materials and waste management at SLAC. A CUPA has broad enforcement responsibilities. The scope has expanded to include the SWPPP, the spill prevention, control, and countermeasures plan (SPCC) and Waste Tire Survey and Inspections, in addition to the following six hazardous material subject areas:

- Hazardous Materials Business Plan/Emergency Response Plan

- Hazardous Waste/Tiered Permitting/Waste Minimization and Pollution Prevention

- Underground Storage Tanks

- Aboveground Storage Tanks (petroleum tanks only)

- California Accidental Release Program

- California Fire Code Hazardous Materials Management Plan (Section 2701.5.1 and 2701.5.2)

\subsubsection{Program Status}

Discussed in the following sections are the status of SLAC's 2012 programs related to hazardous materials life-cycle management, including the hazardous materials business plan, the toxics release inventory (TRI), and the CalARP program. 
For the period between January and December 2012, 50 chemical storage buildings/areas, or 42 percent of the identified buildings/areas were field verified. There was a reduction in the number of storage areas and/or inventory in four of the buildings visited. Usable legacy or unneeded chemicals were removed for redistribution. Products that had expired or had damaged containers or labels were removed for disposal as hazardous waste. This program has been recognized as an effective tool to identify inventory reduction opportunities and provide avenues for reuse and waste reduction.

\subsubsection{Annual Facility Enforcement Inspections}

The San Mateo County CUPA inspected SLAC during July 25 through 27, 2012. There were no violations and only a few minor observations. The inspector indicated that a large improvement in housekeeping was evident from the previous year and was impressed with the positive approach SLAC employees were taking in making compliance part of their daily tasks.

\subsubsection{Hazardous Materials Business Plan Program}

EPCRA, passed in 1986 as Title III of SARA, establishes requirements for emergency planning, notification, and reporting. In California, the requirements of SARA Title III are incorporated into the state's Hazardous Materials Release Response Plan and Inventory Law, more commonly referred to as the HMBP program.

For the 2012 reporting year, SLAC's HMBP was submitted to the San Mateo County CUPA. The 2012 HMBP will be submitted electronically through the California Environmental Reporting System in June of 2013.

The HMBP includes the Hazardous Materials Inventory Statement (HMIS). The inventory consists of all hazardous materials present at SLAC in amounts exceeding the state's aggregate threshold quantities (55 gallons for liquids, 500 pounds (lbs) for solids, and 200 cubic feet for compressed gases) on a building-bybuilding basis. It includes hazardous materials in storage as well as hazardous waste, oil-filled equipment, process and bulk tanks, emergency generators containing fuel, and lead/acid batteries. A portion of the hazardous materials inventory is based on procurement data generated through the CMS. The hazardous waste inventory is based on the database maintained by the WM Group. Mixed waste and radioactive materials data are provided by the RP Department. Inventory of process and bulk tanks are part of the SLAC property and building databases. The CMS maps are used to indicate storage area locations.

The plan also includes the SLAC Consolidated Chemical Contingency Plan. ${ }^{14}$ This plan combines the emergency response requirements for the following programs:

- Hazardous Materials Business Plan

- Hazardous Waste Contingency Plan

- $\quad$ Spill Prevention Control \& Countermeasure Plan

- $\quad$ Risk Management Plan

\subsubsection{Toxics Release Inventory Program}

Under EO 13423, Strengthening Federal Environmental, Energy, and Transportation Management, DOE requires its facilities to comply with Toxic Chemical Release Reporting and Community Right-to-Know requirements (40 CFR 372), more commonly referred to as the TRI program. SLAC provides the required information annually to DOE, which reviews, approves, and sends the TRI information to the USEPA.

14 SLAC National Accelerator Laboratory, 2009. Consolidated Chemical Contingency Plan (SLAC-I-7303A86H-008-R002) 
The TRI report is submitted to USEPA in June each year and reports quantities from the previous calendar year, so the report submitted in June 2012 covered CY 2011. Of the more than 400 listed TRI chemicals, only lead is used at SLAC above its regulatory threshold. As a result, SLAC prepared a TRI Form R for lead and submitted it to the DOE SLAC Site Office (SSO) in June 2012. Approximately 10 percent of the lead removed offsite was recycled. TRI data are available to the public via the USEPA website. ${ }^{15}$

\subsubsection{California Accidental Release Prevention Program}

SLAC has only one regulated chemical that is used above its CalARP threshold: potassium cyanide, which is now used only in the Plating Shop complex. As such, a RMP was prepared and submitted to the CUPA. When the original RMP was prepared, spent plating baths containing cyanide were stored temporarily at the Centralized Hazardous Waste Management Area (CHWMA) pending transport for offsite disposal. However, in 2011 the waste handling procedure was streamlined so that spent plating baths were drummed and picked up by the waste hauler from the area of use, thus eliminating transport to and storage in the CHWMA.

As part of the RMP, worst-case scenarios were developed for the potential release of potassium cyanide, but generated no offsite consequences. Since the impact of such a release was limited to the immediate area of use, SLAC qualified for a Program 1 RMP (the lowest level), whereby a more detailed process hazard assessment and an offsite consequence analysis were not required. The final Program 1 RMP for SLAC was submitted to the CUPA in 2006 and finalized in 2008 after a public comment period. In 2012, the CUPA conducted an onsite assessment of the RMP pursuant to its renewal, which is required every five years. The information in the RMP was updated to reflect current conditions, and the comments from the CUPA were addressed in a timely manner. The revised RMP was submitted to the CUPA in April 2012.

\subsubsection{Aboveground Storage Tank Program}

Aboveground storage tanks (ASTs) are regulated under the authority of the CWA and California's Aboveground Petroleum Storage Act. A listing of active ASTs containing petroleum at SLAC during 2012 is presented in Table 4-3. All of the petroleum tanks at SLAC are constructed of steel with secondary containment. An SPCC plan is required by 40 CFR 112 for all petroleum-containing ASTs greater than 660 gallons in size. The SLAC SPCC plan ${ }^{16}$ was revised in 2008 to ensure compliance with 40 CFR 112 Final Rule prior to its enactment. SLAC does not have any underground storage tanks.

Table 4-3 Aboveground Petroleum Tanks

\begin{tabular}{lllr} 
Petroleum Product & Property Control Number Location & Capacity (gallons) \\
\hline Diesel & 19683 & B112 Master Substation & 2,000 \\
Gasoline/E85 & 21443 & B035 Vehicle Refueling Station & $1,500 / 500$ \\
Vacuum Oil * & 19596 & B020 North Damping Ring & 500 \\
Diesel & 19781 & B505A Generator Fueling & 500 \\
Diesel & 21287 & B007 MCC Generator Fueling & 500 \\
Vacuum Oil * & 19595 & B021 South Damping Ring & 300 \\
X-ray Oil & 15192 & B044 Klystron Test Lab & $364 / 227 / 227$ \\
Compressor Oil & na & B127 Cryogenics & 200 \\
Compressor Oil & 18562 & B127 Cryogenics & 200 \\
* These tanks are used only for short-term storage & na - not available &
\end{tabular}

15 http://www.epa.gov/tri/tridata/index.html

16 Stanford Linear Accelerator Center, Environment, Safety and Health Division, Environmental Protection Department, Spill Prevention, Control, and Countermeasures Plan (SLAC-I-750-0A16M001-R003), September 2008. https://www-internal.slac.stanford.edu/esh/documents internal/SPCC.pdf 


\subsubsection{Toxic Substances Control Act Program}

The objective of TSCA is to minimize the exposure of humans and the environment to chemicals introduced by the manufacturing, processing, and commercial distribution sectors. One portion of TSCA regulates equipment filled with oil or other dielectric fluids that contain PCBs.

TSCA regulations are administered by the USEPA. No USEPA inspections regarding TSCA were conducted at SLAC during 2012.

Transformers with polychlorinated biphenyl (PCB) concentrations of 500 parts per million (ppm) and greater are defined by TSCA as PCB transformers. SLAC has no PCB transformers. Transformers with PCB concentrations equal to or greater than 50 ppm but less than 500 ppm are defined by TSCA as PCBcontaminated transformers. During 2012, SLAC had 105 oil-filled transformers. Only 10 of the 105 oilfilled transformers are PCB-contaminated. The total quantity of PCBs contained in the 105 transformers currently in service is estimated to be approximately $24 \mathrm{lbs}$, based on the volume of oil in each of the 10 transformers and the concentration of PCBs in the oil of that transformer.

\subsubsection{Chemical Management System}

SLAC has been purchasing chemicals solely through Haas Group International (Haas) since August 2005 under its CMS. Haas provides sourcing, purchasing, expediting, and vendor management support for all non-radioactive chemicals and gases used by SLAC. The key objectives of the CMS program at SLAC are to:

- $\quad$ Reduce SLAC’s chemical and gas cost through vendor-leveraged buying power

- $\quad$ Reduce SLAC's risk and space requirements associated with storing, managing and handling chemicals

- $\quad$ Reduce time spent by SLAC researchers and other personnel on sourcing, ordering and tracking chemicals

- $\quad$ Generate chemical usage and compliance reports directly from procurement data

Haas is continuing to work with SLAC on the following new services:

- Haas will support SLAC sustainability efforts by identifying safer or preferred products and setting up opportunities with potential SLAC users to meet the suppliers and test products

- $\quad$ Financial approvals will be based on charge codes to support an organization with more of a matrix structure

- Haas will provide scanners that will allow easier inventory tracking

- Haas will provide secondary Hazard Communication labels in conformance with the new OSHA format

At the end of calendar year 2012, the program had achieved the following:

- Safety performance in the CMS program continues to be excellent; no illnesses/injuries or reportable spills, and contractors have met their training requirements

- $\quad 4,358$ active chemicals were in the catalog

- $\quad$ There were 874 users of the CMS system and 75 work areas

- $\quad$ Purchase order cycle time continues to be less than half a business day on average

\subsection{Waste Management and Minimization}

During the course of its research operations, SLAC generates a variety of waste streams, including both hazardous wastes and non-hazardous wastes. The latter includes industrial waste, municipal solid waste, and scrap metal. 


\subsubsection{Hazardous Waste Management and Minimization}

\subsubsection{Regulatory Framework}

SLAC is a 90-day hazardous waste generator and does not have a Resource Conservation and Recovery Act (RCRA) Part B permit that would allow it to treat, store and/or dispose of it on-site (that is, a treatment, storage, and disposal facility permit) under the federal RCRA regulations. SLAC does have permits to treat a few RCRA-exempt and non-RCRA (that is, California-only) hazardous waste streams (see Section 4.6.1.2 regarding the state-level tiered permit program).

The USEPA has delegated authority for implementing the federal RCRA program to the state of California. In turn, the state has delegated its authority for certain aspects of hazardous waste program oversight to the local CUPA. The San Mateo County Health Services Agency, Environmental Health Division serves as the CUPA with delegated authority to oversee SLAC's hazardous waste management activities.

\subsubsection{Hazardous Waste Treatment: Tiered Permitting Program}

The five tiers of California hazardous waste permits, presented in order of decreasing regulation, are the full permit, standard permit, permit by rule, conditional authorization, and conditional exemption. SLAC operates a total of four hazardous waste treatment units, all under permit by rule. These units are authorized to treat listed or characteristic hazardous wastes. The various units and tiered permit level are summarized in Table 4-4.

Table 4-4 Hazardous Waste Treatment Units Subject to Tiered Permitting

\begin{tabular}{lll} 
Tiered Permit Level & Unit Number & Location/Description \\
\hline Permit by rule & Unit 1A & Cyanide Treatment Tanks \\
Permit by rule & Unit 1B & Metal Finishing Pre-treatment Facility \\
Permit by rule & Unit 1C & Batch Hazardous Waste Treatment Tank \\
Permit by rule & Unit 2 & Metal Finishing Pre-treatment Facility - Sludge Dryer
\end{tabular}

\subsubsection{Hazardous Waste Tracking}

SLAC utilizes a self-developed, site-specific computerized hazardous waste tracking system (WTS). Hazardous waste containers are tracked from the time they are issued to the generator to eventual disposal off-site. The WTS includes fields that generate information required for the SARA Title III, TRI, and TSCA PCBs reports.

\subsubsection{Hazardous Waste Minimization}

SLAC hazardous waste generation rates have been reduced through a combination of waste minimization and pollution prevention techniques, including the following:

- Reducing generation of excess chemicals through CMS

- Converting empty metal containers and drums to scrap metal

- Exchanging chemicals with other users

- Reclassifying waste streams to reduce hazardous waste volumes

- Re-using chemicals

- Returning unused material to the vendor or manufacturer

- Sending electrical equipment offsite for re-use by other organizations

- Utilizing the Department of Defense’s Ozone-Depleting Substance Reserve Program 
SLAC continues to make progress in reducing hazardous waste generated from routine operations, as shown in Figure 4-3. Routine wastes are those wastes associated with SLAC's routine operations and maintenance processes. For 2012, SLAC reduced its hazardous waste generated by routine operations from the 1993 baseline of 147 tons to 16 tons, an 89 percent reduction. The increase in waste reduction from FY 2007 is due to accounting for wastes that were able to be recycled, such as waste oils. Measures will continue to be taken to further reduce hazardous waste by helping smaller generators increase their awareness of waste reduction opportunities, helping them procure less hazardous chemicals, and helping them learn to develop for themselves more focused waste reduction measures for their work areas.

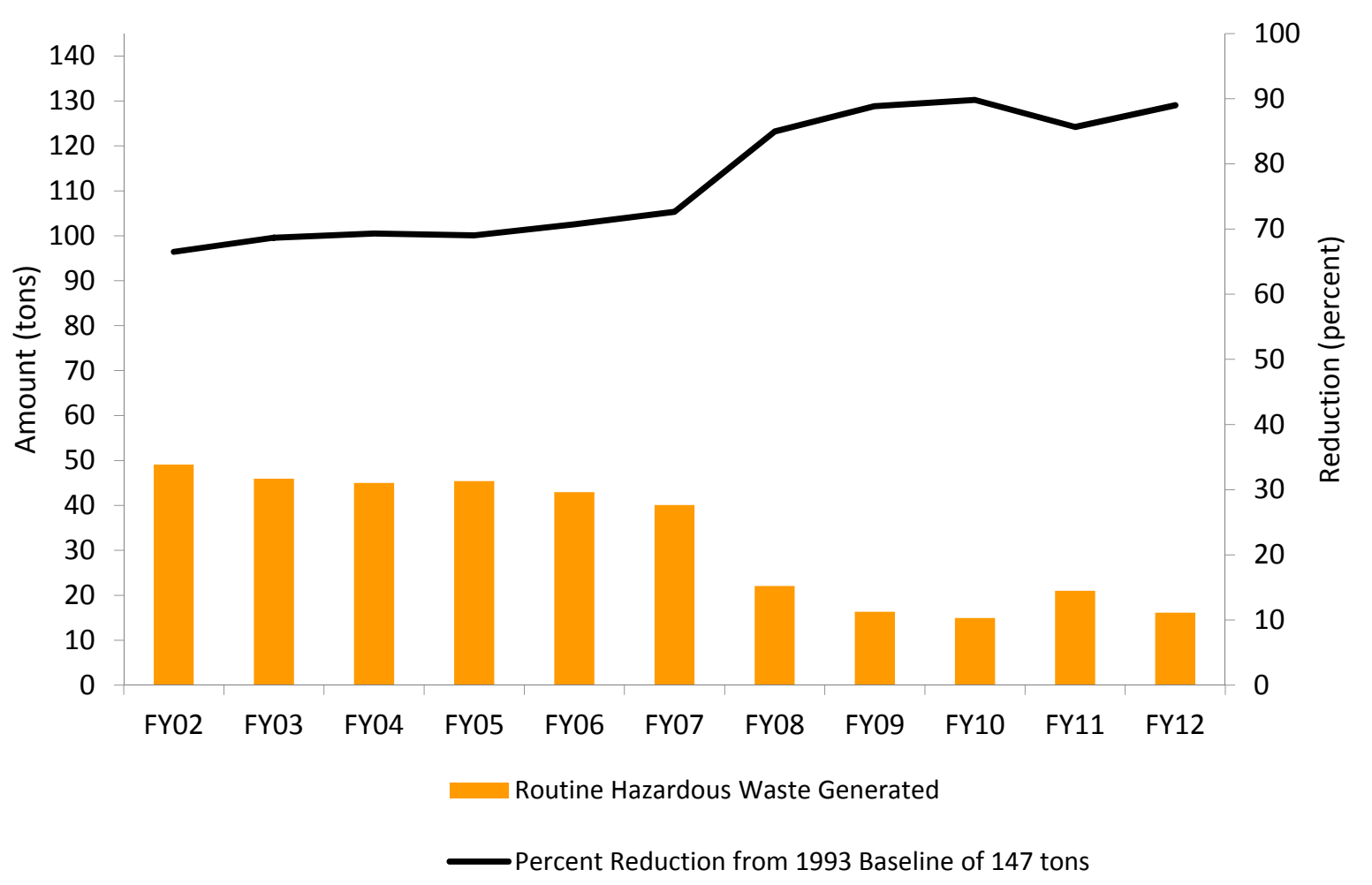

Figure 4-3 Routine Hazardous Waste Generation, 2002-2012

\subsubsection{Non-Hazardous Waste Management and Minimization}

Non-hazardous waste can be grouped into non-hazardous industrial waste and municipal solid waste.

\subsubsection{Non-hazardous Industrial Waste Management}

In addition to its hazardous waste management program, SLAC also operates various projects that involve disposal of non-hazardous waste classified as either non-hazardous industrial or regulated waste. SLAC's WM Group manages industrial waste resulting from SLAC's laboratory operations and remediation operations that, while not classified as hazardous, is not sufficiently "clean" to be disposed of in a municipal or sanitary solid-waste landfill. Examples of industrial wastes include soils contaminated with low levels of petroleum hydrocarbons, PCBs or metals that are classified as non-hazardous but are not acceptable for disposal at municipal landfills. In California, industrial wastes are generally termed Class 2 waste since they are specifically required to be disposed of at Class 2 landfills (these provide an intermediate level of protection to the environment between Class 1 , hazardous waste landfills and Class 3 , municipal solid waste landfills). 


\subsubsection{Municipal Solid Waste Management}

SLAC's Facilities Department operates a municipal solid waste program that collects a variety of recyclable materials as well as regular dumpster refuse. SLAC's Property Control Department operates a salvage operation that sells metal and other industrial recyclables and equipment for their cash value.

The term municipal solid waste refers to the following waste streams generated at SLAC:

- Beverage containers (glass, aluminum, plastic)

- Paper (white paper, mixed paper)

- Cardboard

- Wood

- Scrap metal

- Garden/landscaping waste

- Construction debris (soil and miscellaneous non-hazardous construction and demolition debris)

- Universal waste (fluorescent light bulbs and mercury-containing equipment) and electronic wastes including cathode ray tubes

- $\quad$ Batteries (automotive and common [AA, AAA, C, D, nickel-cadmium, other] batteries)

- Salvage sales and transfers

- Office materials (toner and inkjet cartridges)

- Cafeteria and other food wastes

- Tires

- Trash not otherwise sorted at the source and placed into dumpsters

A site-wide program that recycles mixed paper, beverage containers (glass, aluminum, and plastic), cardboard, and scrap wood has been fully operational for more than 15 years. Collection stations are strategically distributed around the site with each station incorporating anywhere from one to a dozen green containers. Dumpsters for cardboard collection are strategically placed around the site and a specific location is provided for waste wood and non-hazardous construction and demolition debris. Scrap metal and electronic waste is collected and construction materials from building demolition and rehabilitation projects are also recycled.

In 2008, SLAC began collection of compostable food wastes at the onsite cafeteria. These materials are composted offsite at an industrial compost facility. In FY 2012, a zero waste program was implemented at two of SLAC's office buildings, expanding the compost collection to these areas. Paper towel waste is also included in compost collection in these buildings.

For 2012, SLAC recycled 1,146 tons of municipal solid waste and disposed of 420 tons, equating to a diversion rate for municipal solid waste of 73 percent. This is down from an 80 percent diversion last year, which was unusually high due to the recycling of a large quantity of demolition material recycled from the demolition of several old buildings in FY 2011. The contributions of the various waste streams being recycled are shown in Figure 4-4.

\subsubsection{Other Waste Management Activities}

SLAC generates a small quantity of low-level radioactive waste every year; this waste stream is discussed in Chapter 5.

SLAC generates a small quantity of medical waste from the on-site Medical Department. In California, the state Medical Waste Management Act requires proper storage, treatment, and disposal of medical waste. The state program is administered by the California Department of Health Services. 


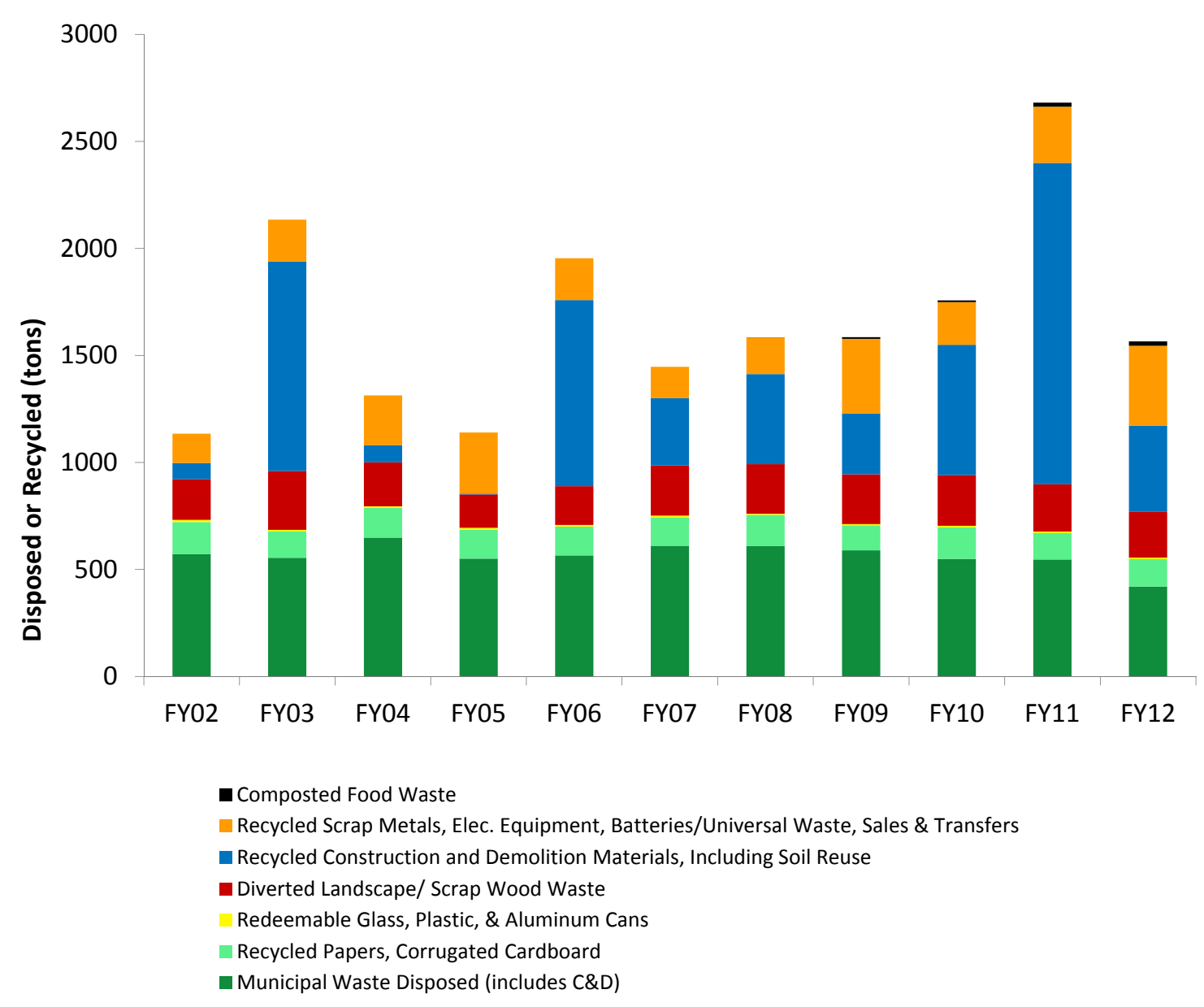

Figure 4-4 Municipal Solid Waste Recycling and Disposal, 2002-2012

\subsection{Sustainability}

SLAC's Site Sustainability Plan, ${ }^{17}$ formerly called the Executable Plan, summarizes SLAC's planned actions and performance status on the sustainability goals derived from EO 13423 and EO 13514, as adopted by DOE in their Strategic Sustainability Performance Plan (SSPP). ${ }^{18}$

A core part of SLAC's Environment, Safety and Health Policy is to "wisely use and conserve natural resources and conduct our activities in a sustainable manner". The EO and DOE SSPP goals complement SLAC's values on sustainability and provide quantifiable objectives and timeframes, consistent over the federal complex.

\subsubsection{Progress on Sustainability Goals}

Included below is a summary of progress on key sustainability goals, in the key areas of energy, GHG, water, sustainable building, fuel/fleet, and waste, as reported in SLAC's Site Sustainability Plan.

\footnotetext{
${ }^{17}$ SLAC National Accelerator Laboratory, Site Sustainability Plan FY 2013, January 10, 2013.

${ }^{18}$ U.S. Department of Energy, 2012 Strategic Sustainability Performance Plan.
} 
Table 4-5 Progress against Select Sustainability Goals of EO 13423/13514 and the DOE SSPP through FY 2012

\begin{tabular}{|c|c|c|}
\hline Category & EO 13423/13514/DOE Goal & Progress \\
\hline Energy Reduction & $\begin{array}{l}\text { Reduce energy intensity } 3 \\
\text { percent/year or } 30 \text { percent by FY } 2015 \\
\text { relative to FY } 2003 \text { baseline. }\end{array}$ & $\begin{array}{l}\text { SLAC has reduced its Energy intensity } \\
\text { by } 47 \text { percent between FY } 2012 \text { and the } \\
\text { FY03 baseline. SLAC will continue to } \\
\text { incorporate energy savings projects with } \\
\text { a good return on investment to reduce } \\
\text { energy intensity. }\end{array}$ \\
\hline Renewable Energy & $\begin{array}{l}\text { Procure } 7.5 \text { percent of the site's } \\
\text { annual electricity consumption from } \\
\text { renewable sources by FY } 2013 \text { and } \\
\text { thereafter. }\end{array}$ & $\begin{array}{l}\text { Renewable Energy Certificates (RECs) } \\
\text { are being purchased equivalent to } 7.5 \\
\text { percent of annual energy. In addition, } \\
\text { Building } 901 \text {, completed in FY } 2010 \text {, was } \\
\text { constructed with an } 18.8 \text { kilowatt roof- } \\
\text { mounted photo-voltaic (PV) system. } \\
\text { Building 052, to be completed in FY } \\
2013 \text {, will also have a roof-top mounted } \\
\text { PV system. }\end{array}$ \\
\hline Greenhouse Gas Reduction & $\begin{array}{l}\text { Reduce Scope } 1 \& 2 \text { GHG emissions } \\
28 \text { percent by FY } 2020 \text { from an FY } \\
2008 \text { baseline }\end{array}$ & $\begin{array}{l}\text { SLAC has reduced Scope } 1 \& 2 \text { GHG by } \\
40 \text { percent in FY } 2012 \text { from the FY } 2008 \\
\text { baseline. SLAC has established a long- } \\
\text { term plan to reduce GHG emissions } \\
\text { through end-of-life replacement with high } \\
\text { efficiency equipment, constructing } \\
\text { energy-efficient buildings and exploring } \\
\text { High-Energy Mission-Specific Facilities } \\
\text { electrical equipment improvements. }\end{array}$ \\
\hline Water Reduction & $\begin{array}{l}\text { Reduce potable water consumption } \\
\text { intensity } 2 \text { percent per year through } \\
2020 \text { or } 26 \text { percent by } 2020 \text { relative to } \\
\text { the FY } 2007 \text { baseline }\end{array}$ & $\begin{array}{l}\text { The total site water usage has decreased } \\
\text { by } 37 \text { percent from the FY } 2007 \text { baseline } \\
\text { through FY 2012. SLAC will continue to } \\
\text { reduce water usage by incorporating } \\
\text { additional meters along with water } \\
\text { conservation technologies for irrigation } \\
\text { and plumbing fixtures. }\end{array}$ \\
\hline
\end{tabular}




\begin{tabular}{|c|c|c|}
\hline Category & EO 13423/13514/DOE Goal & Progress \\
\hline Sustainable Building & $\begin{array}{l}\text { All new construction, major } \\
\text { renovations, and alterations of } \\
\text { buildings greater than a } 5000 \text { gross } \\
\text { square footage must comply with the } \\
\text { Guiding Principles of high performance } \\
\text { and sustainable building (HPSB). }\end{array}$ & $\begin{array}{l}\text { SLAC has met and continues to meet } \\
\text { this goal. Building 901, completed in FY } \\
2010 \text {, received the Leadership in Energy } \\
\text { and Environmental Design (LEED) Gold } \\
\text { certification. The renovation of Building } \\
028 \text { was completed in FY } 2011 \text { and was } \\
\text { designed to meet LEED Gold } \\
\text { certification, which is currently pending. } \\
\text { Currently planned new/major renovation } \\
\text { building projects are designated to be } \\
\text { HPSB. } \\
\text { SLAC goal is for nine buildings to be } \\
\text { compliant with the Guiding Principles by } \\
\text { FY 2015. Two buildings achieved LEED } \\
\text { Gold Certification and four more are } \\
\text { planned to be HPSB's. The } 3 \text { additional } \\
\text { buildings needed to meet the goal are } \\
\text { currently unfunded. }\end{array}$ \\
\hline
\end{tabular}

Petroleum Fuel Reduction $\quad 10$ percent annual increase in fleet alternative fuel consumption by $\mathrm{FY}$ 2015 relative to a FY 2005 baseline.

2 percent annual reduction in fleet petroleum consumption by FY 2020 relative to a FY 2005 baseline.
The SLAC fuel station was converted to dispense E-85 Ethanol alternative fuel in July 2010. SLAC dispensed 282 gallons of E85 in FY 2010, 3,685 gallons in FY 2011, and 3,831 gallons in FY 2012. The FY 2010 to FY 2012 increase is over 1,259 percent, meeting the 10 percent annual increase goal.

SLAC has reduced fuel consumption by 32 percent relative to a FY2005 baseline. This meets the cumulative reduction target of 14 percent between FY 2005 and FY 2012.

In FY 2012, SLAC diverted 65 percent of its non-hazardous solid waste (excluding C\&D debris).

In FY 2012, SLAC diverted 95 percent of the $C \& D$ debris generated from building projects.

\subsection{Environmental Planning}

SLAC's scientific and support facilities were constructed under a clearly conceived planning framework established in the site's original general development plan (1961) and master plan (1966). For over five decades, SLAC facilities expanded within this original framework, but over the years, many small support and storage buildings and more parking demands have crowded the core research areas and obscured the original circulation plan. SLAC ensures that the NEPA requirements are followed on a project-by-project basis. 


\subsubsection{SLAC Long-Range Development Plan}

In December 2002, SLAC published its LRDP, prepared by both SLAC's LRDP Working Committee and the professional land use, environmental, and campus planners from the Stanford University Architect and Planning Office. The most recent revision of the LRDP was completed in 2010.

The LRDP encourages the gradual replacement of small, outdated structures with more efficient and wellplanned development. The plan includes a series of diagrams that overlay planned structures and circulation systems with environmental constraints to intelligently guide the location of future projects. Environmental factors considered in developing the plan include the following:

- Geology and seismicity

- Topography

- Sedimentation and erosion potential

- Hazardous materials

- Considerations of site locations relative to sensitive receptors

- Flooding and wetlands

- Habitat and species protection

- Visual character of SLAC

- Environmental Sustainability

\subsubsection{National Environmental Policy Act}

SLAC developed its formal NEPA program in 1992, and it is jointly administered by the DOE and the EP Department. SLAC staff provides information and technical support to enable DOE and SLAC to determine whether proposed actions will have a significant effect on the environment, as required by the NEPA of 1969.

Environmental aspects that must be considered when conducting the environmental analysis and preparing NEPA documentation commonly include: potential increases in air emissions or hazardous materials usage, waste generation, impacts on wetlands, sensitive species and critical habitats, increases in water consumption, and wastewater discharge.

To be consistent with the DOE NEPA Openness Policy, SLAC posts its Categorical Exclusion (CX) determinations for public availability at the link provided below. ${ }^{19}$ All of the projects, except for the LCLS II EA, were relatively minor in scope and environmental impact, and were all classified as CX. The LCLS II EA was completed in 2012, and based on the findings DOE determined that the proposed action does not constitute a major federal action that would significantly affect the quality of the human environment. A Finding of No Significant Impact (FONSI) was issued on March 7, 2012. Each project was assigned a CX reference number. Completed NEPA documents are forwarded to the DOE SSO and the NEPA Compliance Officer located at the Integrated Support Center, Oak Ridge Office, if necessary, for review and approval. 


\section{Environmental Radiological Program}

\subsection{Introduction}

All members of the public receive radiation doses from natural background radiation and from various human activities. This chapter describes sources of radiation and radioactivity at SLAC and provides an overview of how SLAC's REP Program assesses direct radiation and radioactivity in air, soil and water for the purpose of determining the potential radiation dose to the public and impacts to the environment.

As in past years, the dose that members of the public receive due to SLAC operations is a very small fraction of the dose received from natural background radiation in CY 2012. In addition, the potential radiation dose to the public and the radiation-related impacts to the environment from SLAC operations were significantly below all regulatory limits.

\subsection{Sources of Radiation and Radioactivity}

The 2-mile-long linac at SLAC is located inside a concrete tunnel 25 feet beneath the surface of the ground. Through this underground tunnel, beam particles are accelerated to nearly the speed of light.

Some beam particles strike accelerator components during the acceleration process. When that happens, the decelerating particles may emit secondary radiation in the form of high-energy photons and neutrons. This secondary radiation is present whenever beam particles are accelerated and lost, but that ceases as soon as power to the accelerator is terminated.

The secondary radiation may also make the substances they strike become radioactive. Table 5-1 lists the predominant radioactive elements produced in water or air and their half-lives.

Facilities at SLAC are designed to meet all applicable safety and environmental requirements. Nearly all direct radiation is stopped by the combined shielding on the accelerator structure and the ground or thick concrete walls that surround the accelerator tunnel. SLAC monitors the small fraction of photons and neutrons that pass through the accelerator components, through the surrounding earth or walls, to reach areas outside of the accelerator housing. This direct-radiation monitoring is described in Section 5.3.

SLAC also assesses, measures, and reports on radioactivity as required by its policies and by state or federal regulations. Sections 5.4 through 5.6 and 5.9 describe SLAC's programs to assess and control radioactivity that can be released into the environment. All known releases of radioactive materials are included in the tables in those sections.

Table 5-1 Activation Products in Water or Air

\begin{tabular}{lll} 
Radioactive Element & Half-life & Primarily Produced In \\
\hline Oxygen $\left({ }^{15} \mathrm{O}\right)$ & 123 seconds & Water or air \\
Nitrogen $\left({ }^{13} \mathrm{~N}\right)$ & 10.0 minutes & Air \\
Carbon $\left.{ }^{11} \mathrm{C}\right)$ & 20.3 minutes & Water or air \\
Argon $\left({ }^{41} \mathrm{Ar}\right)$ & 1.8 hours & Air \\
Beryllium $\left({ }^{7} \mathrm{Be}\right)$ & 53.6 days & Water \\
Hydrogen $\left({ }^{3} \mathrm{H}\right)$ & 12.3 years & Water \\
${ }^{3} \mathrm{H}$ - tritium & &
\end{tabular}




\subsection{Monitoring for Direct Radiation}

DOE regulations (DOE O 458.1) require SLAC to demonstrate that radiation and radioactivity from SLAC did not cause any member of the public to receive a radiation dose greater than 100 millirems (mrem, a unit used to quantify radiation dose to humans) during the year. ${ }^{20}$ In CY 2012, the maximum dose that could have been received by a member of the public due to direct radiation from SLAC was 0.53 mrem (5.3E-03 milli-Sievert (mSv), which is the International System of units for dose equivalent). This is 0.53 percent of the 100 mrem regulatory limit. This maximally exposed individual (MEI) is located near the Addison Building Area, a property adjoining SLAC to the north.

During CY 2012, SLAC measured direct radiation at 43 locations around the SLAC site boundary to determine the potential radiation dose to a member of the public. Readings from these site-boundary dosimeters used to measure radiation were recorded each calendar quarter. The annual doses from these dosimeters were used to estimate the doses to the MEI based on continuous occupancy of 24 hours a day, 365 days per year. Landauer Incorporated, accredited by the DOE's Laboratory Accreditation Program and National Voluntary Laboratory Accreditation Program as a dosimeter supplier, provided and processed the dosimeters. Results from these dosimeters were also used to calculate the collective dose to the population (about 5 million) that lives within 80 kilometers $(\mathrm{km})$ (50 miles) of SLAC, which was 0.18 person-rem for CY 2012.

Section 5.8 and Table 5-6 summarize annual doses to the MEI from both direct radiation $\left(0.53 \mathrm{mrem}^{21}\right)$ and airborne radioactivity (1.63E-03 mrem) and show how those doses compare with those from natural background radiation.

\subsection{Assessment of Airborne Radioactivity}

As required by 40 CFR 61 Subpart H, SLAC files an annual report to the USEPA that describes the possible sources, types, and quantities of airborne radioactivity released into the atmosphere. ${ }^{22}$ As detailed below, the resulting dose to the MEI of the off-site general public from CY 2012 releases of airborne radioactivity was $1.63 \mathrm{E}-03 \mathrm{mrem}(1.63 \mathrm{E}-05 \mathrm{mSv})$. This is well below the regulatory limit which requires releases to be limited so that no member of the public receives a dose in excess of $10 \mathrm{mrem}(0.1 \mathrm{mSv})$ in any one year. In addition, there is no individual release point within SLAC exceeding the $0.1 \mathrm{mrem} / \mathrm{y}$ $(0.001 \mathrm{mSv} / \mathrm{y})$ limit for the continuous monitoring requirement; the maximum value was $1.58 \mathrm{E}-03 \mathrm{mrem} / \mathrm{y}$ from the Positron Vault release point. The collective effective dose equivalent to the population within 80 $\mathrm{km}$ of SLAC's site boundary (estimated $5.3 \times 10^{6}$ persons) due to releases of airborne radioactivity at SLAC in CY 2012 was calculated to be 8.6 person-mrem

The Positron Vault release point from the Facility for Advanced Accelerator Experimental Tests (FACET) operations contributes about 87 percent of the total airborne radioactivity released to the atmosphere from SLAC operations in CY 2012. Approximately 97 percent of the 1.63E-03 mrem (MEI dose) can be attributed to emissions from the FACET operations. Approximately 1.25E-03 mrem (or 77 percent of the MEI dose) can be attributed to ${ }^{13} \mathrm{~N}$ radioisotope. The MEI location that corresponds to the highest calculated effective dose equivalent for releases in CY 2012 is at the north end of the Positron Vault, 560 meters from Sector 20. The maximum dose from a single release point (the Positron Vault release point) is 1.58E-03 mrem in CY 2012, which is much less than the $0.1 \mathrm{mrem} / \mathrm{y}$ limit for continuous monitoring requirement.

20 United States Department of Energy, DOE O 458.1, Radiation Protection of the Public And The Environment.

21 Henry Tran, RP-DREP-20130423-MEM-01, CY 2012 SLAC Site Boundary Environmental Dosimeter Monitoring Results \& Public MEI Dose Calculations, April 23, 2013

22 SLAC National Accelerator Laboratory, Environment, Safety \& Health Division. Radiation Protection Department, Radionuclide Air Emissions Annual Report - CY 2012 (June 2013) 
As detailed in the annual NESHAPs report, the released airborne radioactivity was calculated, based on conservative information about accelerator operations in CY 2012. Table 5-2 summarizes the released radioactivity, showing the quantities in curies (Ci). Potential doses to members of the public due to the released radioactivity were determined using the USEPA software CAP88. In addition to providing information on the maximum individual doses, SLAC also assessed and reported the collective dose to the population that lives within $80 \mathrm{~km}$ (50 miles) of SLAC, which was 8.6 person-mrem for CY 2012.

Table 5-2 and Table 5-6, as well as Section 5.8, provide a summary of the results and information on how the maximum possible doses compare with natural background radiation.

Table 5-2 Airborne Radioactivity Released in CY 2012

\begin{tabular}{llr} 
Category & Radioactive Element & Activity (Ci) \\
\hline Tritium & Hydrogen $\left({ }^{3} \mathrm{H}\right)$ & $\mathrm{n} / \mathrm{a}$ \\
Krypton-85 & Krypton $\left({ }^{85} \mathrm{Kr}\right)$ & $\mathrm{n} / \mathrm{a}$ \\
Noble gases $\left(\mathrm{T}_{1 / 2}<40\right.$ days $)$ & Argon $\left({ }^{41} \mathrm{Ar}\right)$ & 0.029 \\
Short-lived activation products $\left(\mathrm{T}_{1 / 2}<3 \mathrm{hr}\right)$ & Oxygen $\left({ }^{15} \mathrm{O}\right)$ & 0.623 \\
& Nitrogen $\left({ }^{13} \mathrm{~N}\right)$ & 1.163 \\
& Carbon $\left({ }^{11} \mathrm{C}\right)$ & 0.125 \\
Other activation products $\left(\mathrm{T}_{1 / 2}>3 \mathrm{hr}\right)$ & $\mathrm{n} / \mathrm{a}$ & $\mathrm{n} / \mathrm{a}$ \\
Total radioiodine & $\mathrm{n} / \mathrm{a}$ & $\mathrm{n} / \mathrm{a}$ \\
Total radiostrontium & $\mathrm{n} / \mathrm{a}$ & $\mathrm{n} / \mathrm{a}$ \\
Total uranium & $\mathrm{n} / \mathrm{a}$ & $\mathrm{n} / \mathrm{a}$ \\
Plutonium & $\mathrm{n} / \mathrm{a}$ & $\mathrm{n} / \mathrm{a}$ \\
Other actinides & $\mathrm{n} / \mathrm{a}$ & $\mathrm{n} / \mathrm{a}$ \\
Total & & 1.939 \\
$\mathrm{n} / \mathrm{a}-$ not applicable & & \\
$\mathrm{T}_{1 / 2}-$ half life & &
\end{tabular}

\subsection{Assessment of Radioactivity in Water}

Three types of water are monitored for radioactivity at SLAC: industrial wastewater, stormwater, and groundwater. This section summarizes the CY 2012 monitoring and results for each water type.

\subsubsection{Industrial Wastewater}

Federal and state regulations (10 CFR 20.2003 and 17 CCR 30253) limit the radioactivity in industrial wastewater that SLAC releases to the sanitary sewer system. In CY 2012, SLAC released 0.002 percent of the applicable limits (only $1.1 \times 10^{-4} \mathrm{Ci}$ for tritium).

Throughout CY 2012, SLAC sampled and analyzed wastewater discharges. Total activity released during CY 2012 is summarized in Table 5-3.

As required by regulations, at the end of each calendar quarter of CY 2012, SLAC reported the results of wastewater monitoring and discharge to the SBSA. ${ }^{23}$

23 Stanford Linear Accelerator Center, Environment, Safety, and Health Division, Radiation Protection Department, Radioactivity in Industrial Wastewater for the Period of 1 January 2012 to 31 March 2012, for the Period of 1 April 2012 to 30 June 2012, for the Period of 1 July 2012 to 30 September 2012, and for the Period of 1 October 2012 to 31 December 2012 
Table 5-3 Radioactivity in Wastewater Released into Sanitary Sewer in CY 2012

\begin{tabular}{|c|c|c|c|}
\hline Category & Radioactive Element & Activity (Ci) & $\begin{array}{r}\text { al Release } \\
\text { Limit (Ci) }\end{array}$ \\
\hline Tritium & Hydrogen $\left({ }^{3} \mathrm{H}\right)$ & $1.1 \times 10^{-4}$ & 5 \\
\hline \multirow[t]{2}{*}{ Activation products $\left(\mathrm{T}_{1 / 2}>3 \mathrm{hr}\right)$} & 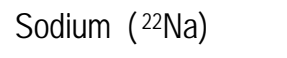 & 0 & 1 * \\
\hline & Beryllium ( $\left.{ }^{7} \mathrm{Be}\right)$ & 0 & \\
\hline Total radioiodine & $\mathrm{n} / \mathrm{a}$ & 0 & \\
\hline Total radiostrontium & $\mathrm{n} / \mathrm{a}$ & 0 & \\
\hline Total uranium & $\mathrm{n} / \mathrm{a}$ & 0 & \\
\hline Plutonium & $\mathrm{n} / \mathrm{a}$ & 0 & \\
\hline Other actinides & $\mathrm{n} / \mathrm{a}$ & 0 & \\
\hline
\end{tabular}

Table 5-4 summarizes the historical results of wastewater monitoring for CY 2002 through CY 2012. The final column of the table compares the radioactivity discharged by SLAC into the sanitary sewer with the annual limit for such discharges set by federal and state regulation. Each year, the quantities and types of radioactivity in wastewater discharged depend on past accelerator operations and on details of wastewater handling.

Table 5-4 Summary of Radioactivity in SLAC Wastewater, CY 2002- 2012

\begin{tabular}{llrr} 
Year & \multicolumn{1}{c}{$\begin{array}{c}\text { Radioactive } \\
\text { Element }\end{array}$} & $\begin{array}{r}\text { Percentage of } \\
\text { Annual Limit }(\mathrm{Ci})\end{array}$ \\
\hline 2002 & Hydrogen $\left({ }^{3} \mathrm{H}\right)$ & $2.4 \times 10^{-2}$ & 0.5 \\
& Sodium $\left({ }^{22} \mathrm{Na}\right)$ & $5.1 \times 10^{-5}$ & $1.4{ }^{*}$ \\
& Beryllium $\left({ }^{7} \mathrm{Be}\right)$ & $1.4 \times 10^{-2}$ & \\
2003 & Hydrogen $\left({ }^{3} \mathrm{H}\right)$ & $4.1 \times 10^{-4}$ & 0.008 \\
2004 & Hydrogen $\left({ }^{3} \mathrm{H}\right)$ & $2.0 \times 10^{-2}$ & 0.4 \\
2005 & Hydrogen $\left({ }^{3} \mathrm{H}\right)$ & $1.4 \times 10^{-3}$ & 0.03 \\
2006 & Hydrogen $\left({ }^{3} \mathrm{H}\right)$ & $1.2 \times 10^{-3}$ & 0.02 \\
2007 & Hydrogen $\left({ }^{3} \mathrm{H}\right)$ & 2.3 & 46 \\
2008 & Hydrogen $\left({ }^{3} \mathrm{H}\right)$ & 1.8 & 36 \\
2009 & Hydrogen $\left({ }^{3} \mathrm{H}\right)$ & $9.1 \times 10^{-5}$ & 0.002 \\
2010 & Hydrogen $\left({ }^{3} \mathrm{H}\right)$ & $1.2 \times 10^{-2}$ & 0.24 \\
2011 & Hydrogen $\left({ }^{3} \mathrm{H}\right)$ & $2.08 \times 10^{-4}$ & 0.004 \\
2012 & Hydrogen $\left({ }^{3} \mathrm{H}\right)$ & $1.1 \times 10^{-4}$ & 0.002
\end{tabular}

* ${ }^{22} \mathrm{Na}$ and ${ }^{7} \mathrm{Be}$ combined. Excluding ${ }^{3} \mathrm{H}$ (for which there is a $5 \mathrm{Ci}$ annual limit), there is a $1 \mathrm{Ci}$ limit for the combined activity of all radioactive elements released during the calendar year 


\subsubsection{Stormwater}

The program for monitoring stormwater is described in Section 4.4 of this report. In CY 2012 (and in all previous years), no radioactivity above natural background was found in any stormwater or storm drain sediment samples.

SLAC reported the results of the CY 2012 stormwater monitoring (including checks for radioactivity) to the RWQCB. ${ }^{24}$

\subsubsection{Groundwater}

Throughout CY 2012, SLAC performed in-house analysis of water samples from monitoring wells for the presence of radioactivity each time the wells were sampled under SLAC's groundwater Self-Monitoring Program (SMP) as described in Chapter 6 of this report. The SMP includes a Groundwater Sampling Plan which outlines the frequency of sampling the wells. Groundwater samples collected as part of the SMP are also sent to an external California-certified laboratory for independent tritium analysis. The results from the external laboratory are in general agreement with the in-house analysis.

With the exception of two of the four monitoring wells listed in Table 5-5, no radioactivity above natural background was detected in any of the groundwater samples. SLAC has over 100 wells that are sampled for tritium. The detected concentrations of tritium in the water samples summarized in Table 5-5 were below federal and state limits set for tritium in drinking water. The drinking water standard for tritium is 20,000 picoCuries per liter (pCi/L) under 22 CCR 64443 and 40 CFR 141.66. In addition, groundwater is not used at SLAC for any purpose because of its very low well yields. Even if there was an adequate supply of groundwater available at SLAC, it could not be used as drinking water due to the naturally high content of total dissolved solids (TDS).

Table 5-5 Summary of Tritium Concentrations Measured in Four Monitoring Wells in CY 2012

\begin{tabular}{|c|c|c|c|c|c|}
\hline Period & (Month) & $\begin{array}{l}\text { Jan. to } \\
\text { March }\end{array}$ & April to June & July to Sept. & Oct. to Dec. \\
\hline EXW-4 & $\begin{array}{l}\mathrm{Avg}^{3} \mathrm{H}(\mathrm{pCi} / \mathrm{L}) \\
\text { percent of DWS } \\
\text { No. of Samples }\end{array}$ & $\begin{array}{r}1562 \\
8 \\
1\end{array}$ & $\begin{array}{r}1493 \\
7 \\
1\end{array}$ & $\begin{array}{r}1251 \\
6 \\
1\end{array}$ & $\begin{array}{r}1048 \\
5 \\
1\end{array}$ \\
\hline MW-30 & $\begin{array}{l}\text { Avg }^{3} \mathrm{H}(\mathrm{pCi} / \mathrm{L}) \\
\text { percent of DWS } \\
\text { No. of Samples }\end{array}$ & $\begin{array}{r}<500^{2} \\
\text { na } \\
1\end{array}$ & $\begin{array}{r}<500^{2} \\
\text { na } \\
1\end{array}$ & $\begin{array}{r}<500^{2} \\
\text { na } \\
1\end{array}$ & $\begin{array}{r}<500^{2} \\
\text { na } \\
1\end{array}$ \\
\hline MW-81 & $\begin{array}{l}\mathrm{Avg}^{3} \mathrm{H}(\mathrm{pCi} / \mathrm{L}) \\
\text { percent of DWS } \\
\text { No. of Samples }\end{array}$ & $\begin{array}{r}<500^{2} \\
\text { na } \\
1\end{array}$ & $\begin{array}{r}<500^{2} \\
\text { na } \\
1\end{array}$ & $\begin{array}{r}<500^{2} \\
\text { na } 1\end{array}$ & $\begin{array}{r}<500^{2} \\
\text { na } \\
1\end{array}$ \\
\hline MW-94 & $\begin{array}{l}\text { Avg }{ }^{3} \mathrm{H}(\mathrm{pCi} / \mathrm{L}) \\
\text { percent of DWS } \\
\text { No. of Samples }\end{array}$ & $\begin{array}{r}2950 \\
15 \\
1\end{array}$ & $\begin{array}{r}4642 \\
23 \\
1\end{array}$ & $\begin{array}{r}4826 \\
24 \\
1\end{array}$ & $\begin{array}{r}3399 \\
17 \\
1\end{array}$ \\
\hline
\end{tabular}

1 DWS - Drinking Water Standard: 20,000 pCi/L for tritium

$2500 \mathrm{pCi} / \mathrm{L}$ was the minimum tritium concentration that was detectable by SLAC in CY 2012

na - not available

\subsection{Assessment of Radioactivity in Soil}

Throughout CY 2012, SLAC did not need to conduct sampling and analysis of radioactivity in soil because there were no excavations in regions that can potentially be activated from SLAC operations.

24 SLAC National Accelerator Laboratory, Environment, Safety, and Health Division, Environmental Protection Department, 2012 -2013 Annual Report for Stormwater Discharges Associated with Industrial Activities (June 30, 2013, submitted to San Francisco Bay RWQCB) 


\subsection{Release of Property Containing Residual Radioactive Material}

All property, both real and personal, exposed to any process at SLAC that could cause it to have the potential for surface or volumetric contamination has to be measured using appropriate field instruments having increasing levels of sensitivity. SLAC also uses process knowledge in addition to radiological surveys to ensure that the material meets the release criteria for recycling metals. The materials are verified to have no detectable radioactivity before they are permitted to be released from radiological controls. At SLAC, property that has any detectable radioactivity is identified as radioactive, and is either retained for appropriate reuse on site or is disposed of as radioactive waste. Only material which did not have detectable radioactivity can be released from radiological controls. Therefore, property releases at SLAC do not add to the potential public dose.

Following the above protocol, 118 tons of metal were recycled from the PEP-II accelerator and BaBar detector in CY 2012. These metals consisted of copper and aluminum conductor from PEP-II and BaBar; iron shield blocks; steel and stainless steel accelerator components from PEP-II including vacuum chambers, elbows, bellows, fasteners, and structural components; as well as brass plate from BaBar detector. A radiation portal gate monitor has been installed and is in operation at SLAC and is being used as a final screening of full truckloads of metals prior to release to the recycling center.

\subsection{Potential Dose to the Public}

The maximum possible dose to members of the public due to SLAC operations are very small compared with doses from natural background radiation and are well below all regulatory limits.

Table 5-6 summarizes the dose results for the two modes that were the potential contributors to public radiation dose in CY 2012, namely direct radiation $(0.53 \mathrm{mrem})$ and airborne radioactivity (1.63E-03 mrem). Releases of radioactivity in water and property were too small to result in a radiation dose to a member of the public under any credible scenario. Table 5-6 also compares the CY 2012 dose results with regulatory limits and natural background.

The MEI due to direct radiation is located near the business offices in the Addison Building area (590 meters from Sector 20), which is located immediately north of SLAC. Like previous years' calculations, the CY 2012 calculation of the MEI dose does not include any dose reduction for hills that may lie between the locations of dose measurements and the MEI. However, since 2003, the effects of air attenuation for direct photon radiation calculations (a factor of 40 ) are taken into account. 
Table 5-6 Summary of Potential Annual Doses due to SLAC Operations in CY 2012

\begin{tabular}{|c|c|c|c|c|}
\hline & $\begin{array}{l}\text { Maximum } \\
\text { Dose to } \\
\text { General Public } \\
\text { - Direct } \\
\text { Radiation }\end{array}$ & $\begin{array}{l}\text { Maximum Dose to } \\
\text { General Public - } \\
\text { Airborne } \\
\text { Radioactivity }\end{array}$ & $\begin{array}{l}\text { Maximum Dose } \\
\text { to General } \\
\text { Public - } \\
\text { Airborne + } \\
\text { Direct }\end{array}$ & $\begin{array}{l}\text { Collective Dose } \\
\text { to Population within } 80 \mathrm{~km} \text { of } \\
\text { SLAC }\end{array}$ \\
\hline Dose from SLAC & 0.53 mrem & 1.63E-03 mrem & 0.53 mrem & $\begin{array}{l}0.18 \text { (direct) }+0.0086 \text { (air) } \\
=0.1886 \text { person-rem }\end{array}$ \\
\hline $\begin{array}{l}\text { DOE Radiation Protection } \\
\text { Standard }\end{array}$ & 100 mrem & $10 \mathrm{mrem}$ & 100 mrem & n/a \\
\hline $\begin{array}{l}\text { SLAC Maximum Dose as } \\
\text { Percentage of DOE Standard }\end{array}$ & $0.53 \%$ & $0.0163 \%$ & $0.53 \%$ & $\mathrm{n} / \mathrm{a}$ \\
\hline $\begin{array}{l}\text { Dose from Natural } \\
\text { Background25 }\end{array}$ & 100 mrem & 200 mrem & 300 mrem & $\begin{array}{c}1,667,000 \\
\text { person-rem }\end{array}$ \\
\hline $\begin{array}{l}\text { SLAC Maximum Dose as } \\
\text { Percentage of Natural } \\
\text { Background }\end{array}$ & $0.53 \%$ & $0.0008 \%$ & $0.18 \%$ & 1.13E-05 \% \\
\hline
\end{tabular}

Table 5-7 presents the maximum dose potentially received by a member of the public from both direct radiation and airborne radioactivity due to SLAC operations in CY 2002 through CY 2012 and compares it with the average dose due to natural background radiation and radioactivity.

Table 5-7 Potential Annual Dose (mrem/year [yr]) to Maximally Exposed Individual, CY 2002-2012

\begin{tabular}{cccc} 
Year & $\begin{array}{c}\text { SLAC Direct and Airborne } \\
\text { Radiation (mrem) }\end{array}$ & $\begin{array}{c}\text { Average, Total Natural } \\
\text { Background Radiation (mrem) }\end{array}$ & $\begin{array}{c}\text { Percentage of SLAC Dose } \\
\text { to Natural Background }\end{array}$ \\
\hline 2002 & 2.1 & 300 & 0.7 \\
$2003{ }^{*}$ & 0.2 & 300 & 0.07 \\
2004 & 0.2 & 300 & 0.07 \\
2005 & 0.3 & 300 & 0.1 \\
2006 & 0.5 & 300 & 0.2 \\
2007 & 0.1 & 300 & 0.03 \\
2008 & 0.05 & 300 & 0.02 \\
2009 & 0.06 & 300 & 0.02 \\
2010 & 0.13 & 300 & 0.04 \\
2011 & 0.42 & 300 & 0.14 \\
2012 & 0.53 & 300 & 0.18
\end{tabular}

* Starting with the 2003 calculations, the effects of air attenuation were taken into account.

25 National Council on Radiation Protection and Measurement, NCRP Report No. 94, Exposure of the Population in the United States and Canada from Natural Background Radiation, http://www.ncrponline.org/Publications/94press.html 


\subsection{Biota Dose}

The DOE technical standard, A Graded Approach for Evaluating Radiation Doses to Aquatic and Terrestrial Biota (DOE-STD-1153-2002), suggests that DOE facilities protect plants and animals by assuring the following dose rates due to "exposure to radiation or radioactive material releases" into the applicable environment are not exceeded:

- Aquatic animals: should not exceed $1 \mathrm{rad} / \mathrm{day}$

- Terrestrial plants: should not exceed $1 \mathrm{rad} /$ day

- Terrestrial animals: should not exceed $0.1 \mathrm{rad} /$ day

Rad, instead of rem, is used here as rad is the unit to quantify radiation dose in a material, in this case animal and plants.

\subsubsection{Dose to Biota from Direct Radiation}

In CY 2012, SLAC monitored dose and dose rate at approximately 580 on-site locations (most outside accelerator shielding and some inside shielding) using passive radiation dosimeters posted for six month periods. For each period, the average dose rate among these 580 dosimeters was found to be less than $0.0003 \mathrm{rad} / \mathrm{day}^{26}$ (dominated by those inside shielding), and the maximum dose rate was less than 0.012 $\mathrm{rad} /$ day (inside shielding). Based on the results of this monitoring program and the fact that the animal populations could not have been present except in areas with the low dose rates outside shielding, doses to plant and animal populations at SLAC were well within the limits of the DOE standard throughout CY 2012.

\subsubsection{Dose to Biota from Activation Products}

In CY 2012, SLAC tested water and soil samples for the presence of radioactivity in excess of natural background, as described in Sections 5.5 and 5.6. Tritium was occasionally found in industrial wastewater in CY 2012, but plant and animal populations have no opportunity to come in contact with industrial wastewater at SLAC. Since the radioactivity concentrations in these sampled media are much lower than from direct radiation, there is no possibility that plants or animals will receive dose rates that exceed the limits of the standard due to radioactive activation products at SLAC.

In CY 2012, no groundwater was found with tritium concentrations in excess of the human drinking water standard of 20,000 pCi/L set by state and federal regulations. Section 5.5.3 summarizes the CY 2012 results of monitoring for radioactivity in groundwater. There is no potential that plants or animals will receive dose rates that exceed the limits of the standard due to activation products in groundwater at SLAC.

\subsection{Low-level Radioactive Waste Management}

SLAC generates low-level radioactive waste (LLRW) sporadically from routine operations, repairs, and special projects or experiments. Non-routine operations generate the bulk of LLRW at SLAC, amounting to 1,053 cubic feet in CY 2012. Additionally, SLAC generated a total of 81 cubic feet of routine low level wastes of which, 43 cubic feet were mixed LLRW. The minimization of LLRW is accomplished through training of the waste generators, careful planning of work operations thorough survey and characterization of materials, segregation, reuse, and volume reduction when applicable.

SLAC continues to manage its LLRW in compliance with all applicable laws and regulations and DOE directives. During CY 2012, SLAC shipped 539 cubic feet of LLRW (a total of $90 \mathrm{mCi}$ and 7,072

26

RP Note RP-12-15, Monitoring Results for Integrated Area Dose around SLAC for the period from January 2012 through June 2012 and Monitoring Results for Integrated Area Dose around SLAC for the period from July 2012 through December 2012. 
kilograms) to appropriately permitted and licensed treatment and disposal facilities for low-level radioactive waste. SLAC disposed of 200 cubic feet of LLRW generated through the PEP decontamination and decommissioning project. Legacy waste accounted for 5 percent of the volume shipped for disposal during CY 2012. SLAC permanently removed 98 sealed sources from the site inventory; these sources were shipped to Energy Solutions for processing prior to burial at the Nevada National Security Site, formerly the Nevada Test Site. 


\section{Groundwater Protection and Environmental Restoration}

\subsection{Introduction}

This chapter describes the groundwater protection and environmental restoration programs at SLAC, including the regulatory framework, site cleanup objectives, an overview of potential chemical impacts, summary of most recent restoration activities, and SLAC’s groundwater monitoring program.

\subsection{Background Conditions}

The document The Geology of SLAC ${ }^{27}$ provides a detailed description of the geology of SLAC. Based on many tests in exploratory borings and wells, the hydraulic conductivity of SLAC's bedrock is overall much less than the range of that generally accepted as representing natural aquifer material. The groundwater at SLAC is not used as a drinking water source because of low yield as well as naturally occurring high TDS content.

\subsection{Areas with Potential Impact from Chemicals}

A SLAC 1994 report entitled Summary and Identification of Potentially Contaminated Sites ${ }^{28}$ provides a summary of areas that may have been impacted by chemicals of concern from past SLAC operations. Information for the report was collected from a variety of sources including incident reports, aerial photographs, operations records, reports on previous investigations, and interviews with personnel throughout the facility. Additional environmental summary documents were completed in 2006 through 2012. The 2006 Environmental Baseline Report ${ }^{29}$ (EBR) provided an inventory of facilities and areas at SLAC that were considered to have the potential to have chemical impacts, and summarized the results of the environmental investigations and remediation activities that had occurred. The EBR identified COPCs, defined Investigation Areas, and provided a decision process for determining which areas still required additional actions. At that time, The Work Plan for the Remedial Investigation and Feasibility Study ${ }^{30}$ (RI/FS WP) provided additional description and updated the status of investigation areas, defined the four Operable Units (OUs) at SLAC, and described the framework for completing the environmental investigations and remedial actions at the facility. As discussed further in Section 6.5, remedial investigations and remedial actions at each OU have been completed at SLAC in accordance with the Board Order and RI/FS WP.

27 Stanford Linear Accelerator Center, The Geology of SLAC (SLAC-I-750-3A33X-002, November 2006) http://www-group.slac.stanford.edu/esh/groups/ep/geology/geologicreport.pdf

28 ESA Consultants, Stanford Linear Accelerator Center, Summary and Identification of Potentially Contaminated Sites (February 1994)

29 Sapere Consulting, Stanford Linear Accelerator Center Environmental Baseline Report (February 2006)

30 Stanford Linear Accelerator Center, Work Plan for the Remedial Investigation and Feasibility Study (SLAC-I-750-A17M-008, May 2006) 


\subsection{Strategies for Controlling Potential Sources of Chemicals}

Strategies for chemical source control involve measures to control known soil or groundwater impacts as discussed in this chapter, and procedures and requirements to avoid practices that could adversely affect soil and groundwater as discussed in Chapter 4 . These procedures include the site's SWPPP ${ }^{31}$ which discusses BMPs for preventing adverse impacts from spills and operations at SLAC.

\subsection{Restoration Activities}

SLAC first began environmental investigation and restoration activities in the mid-1980s and by 1991 had developed a comprehensive environmental restoration program. Program activities range from discovery and characterization to remediation and long-term monitoring or maintenance where required.

The general restoration approach at SLAC is to accomplish the following steps:

- Identify sites with actual or potential impacts (involving soil, groundwater, surface water, and/or air)

- Prioritize impacted sites based on site complexity, nature of chemical impacts, associated risks, remaining data needs, and projected remedy

- Investigate sites and identify remedies that protect human health and the environment, beginning with the highest-priority sites

- Implement remedies and monitor for effectiveness

As of 2012, SLAC had generally reached and continued work towards completion of the fourth step. Restoration work conducted to date generally consists of two categories, soil excavation to remove localized areas of PCB or other chemically-impacted soils, and extraction and treatment of solventimpacted soil vapor and groundwater. There are four major areas impacted with COPCs in groundwater: the Former Hazardous Waste Storage Area, Former Solvent Underground Storage Tank Area, the Test Lab/Central Lab area, and the Plating Shop Area. Each of these is described in Section 6.7, along with a description of sites where soil removal has recently been conducted.

\subsection{Regulatory Framework}

In October 2009, the RWQCB issued an updated Board Order (No. R2-2009-0072) for SLAC for the investigation and remediation of impacted soil and groundwater resulting from historical spills and leaks that occurred during the course of operations at SLAC. The Board Order addresses release sites at SLAC and consolidates the investigation and cleanup activities at the facility. It also rescinds the Board Order issued in May 2005. In January 2006, the RWQCB was designated by the State of California as the Administering Agency (i.e., lead agency) for the environmental cleanup work at SLAC. ${ }^{32}$ As the lead agency, the RWQCB has the responsibility to determine the adequacy and extent of cleanup, issue necessary authorizations and permits, and following the determination that an approved remedy has been accomplished, issues a certificate of closure. The RWQCB has specified site cleanup to residential standards for un-restricted land use, ${ }^{33}$ consistent with how the SLAC property is zoned.

31 Stanford Linear Accelerator Center, Environment, Safety, and Health Division, Environmental Protection and Restoration Department, SLAC Stormwater Pollution Prevention Plan (SLAC-I-7500A16M-002)

32 California Environmental Protection Agency, Site Designation Committee Resolution No. 06-01 (January 2006)

33 Regional Water Quality Control Board, Approval of Stanford Linear Accelerator Center Long Range Redevelopment Plan (November 18, 2005) 
In accordance with the Board Order and the RI/FS WP, the framework for ongoing cleanup activities parallels as practicable the CERCLA RI/FS Process, whereby a sequential series of documents are prepared for accessible areas within each of the four OUs established at SLAC. These OUs include: 1) the Groundwater VOC OU, 2) the Tritium OU, 3) the West SLAC/Campus Area/IR-8 Drainage Channel OU (WSLAC OU), and 4) the Research Yard/SSRL/IR-6 Drainage Channel OU (RY OU). However, it is noted that while SLAC follows the CERCLA RI/FS process, SLAC was not listed in the National Priorities List as a Superfund site because the USEPA determined that the conditions at the site did not warrant inclusion.

Many of the RI/FS documents required under the Board Order for each OU have been completed or are under preparation. These documents include a detailed summary of the nature and extent of the impact (RI reports), baseline human health and ecological risk assessments (Risk Assessment or RA Reports), followed by a thorough review of remedial options (Feasibility Study or FS Reports) to address any remaining soil and groundwater remediation issues at the site. The reports take into consideration the removal actions already implemented and incorporate, in accordance with DOE guidance, an assessment of the NEPA values for the interim actions planned for the OU. Remedial alternatives are evaluated in the FS reports against a number of criteria including effectiveness, ability of implementation, cost, and community acceptance. Upon RWQCB approval of the RI, RA, and FS reports, as applicable, Remedial Action Plans (RAP) and Remedial Design (RD) reports are prepared for each OU. The RAPs outline the steps required to implement the proposed remedial actions required to achieve the cleanup objectives for the site and the $\mathrm{RD}$ reports provide the engineering design details for the remedial action. Table 6-1summarizes the status for the RI/FS deliverables required under the Board Order as of the end of calendar year 2012.

Table 6-1 RWQCB Order Deliverables Status

\begin{tabular}{cccccc} 
Operating Unit & RI Report & $\begin{array}{c}\text { RA } \\
\text { Report }\end{array}$ & FS Report & RAP & RD Report \\
\hline Groundwater VOC & Complete & Complete & Complete & Complete & Complete \\
WSLAC & $\begin{array}{c}\text { Part A - Completed } \\
\text { Part B - Under preparation }\end{array}$ & - & - & - & - \\
RY & Complete & Draft complete & $\begin{array}{c}\text { Under } \\
\text { preparation }\end{array}$ & - & - \\
Tritium & Complete & Complete & Complete 34 & n/a ${ }^{35}$ & n/a \\
n/a - not applicable & & & & &
\end{tabular}

Regular meetings regarding site cleanup status also continued in 2012, regularly attended by the Core Team, a decision-making body consisting of representatives from the RWQCB, DOE Office of Science, DOE Environmental Management, Stanford University, and SLAC. As needed, members of the technical team are present at these meetings. The Core Team meetings are moderated by an outside facilitator.

\subsection{Groundwater Characterization Monitoring Network}

As part of the Board Order, SLAC implements a SMP that includes a Groundwater Sampling Plan with a schedule for collecting groundwater samples from extraction and monitoring wells, surface water samples, and sediment samples from select catch basins and drainage channels. The SMP Groundwater Sampling and Analyses Plan, ${ }^{36}$ outlines the frequency at which monitoring samples are to be collected and the

34 A Tritium OU Monitoring Plan was prepared in lieu of a FS Report and approved by the RWQCB

35 Per the RWQCB approved Tritium RI Report, a Remedial Action Plan (RAP) and Remedial Design

(RD) Report are not necessary at this time

36 Stanford Linear Accelerator Center, Self-Monitoring Program Sampling and Analysis Plan, Revision 3 (SLAC-I-750-0A32M-005 R002) 2012. 
analyses to be performed on each sample. During 2012, the plan was revised and submitted to the Board which approved all changes made to the plan. Figures 6-1 through 6-3 show the areas where wells are used for monitoring.

The six locations where plume monitoring occurs are listed below and shown on Figures 6-2 and 6-3.

- Former Hazardous Waste Storage Area (FHWSA)

- Former Solvent Underground Storage Tank (FSUST) Area

- Test Lab and Central Lab Area (TL/CL)

- Plating Shop Area (PSA)

- Lower Salvage Yard (LSY)

- $\quad$ Beam Dump East (BDE)

SLAC has 178 wells across the site, 64 of which are extraction wells, seven wells are used as peizometers (wells only used to measure groundwater elevation), three wells are inactive, and the remaining 104 wells are used as monitoring wells. Of the 104 monitoring wells, 91 wells are used to monitor general groundwater quality and COPCs in the major areas of the facility that historically or currently store, handle, or use chemicals, and 13 wells are used for general site-wide surveillance. Table 6-2 summarizes the wells at SLAC by location, number of wells per location, and purpose of the wells.

The COPCs in groundwater at SLAC are primarily VOCs and to a lesser extent semi-volatile organic compounds (SVOCs). Four of the six locations, have remediation systems that extract soil vapor and groundwater. Preliminary Cleanup Goals (PCGs) at SLAC have been established for groundwater and soil vapor. The systems at the FSUST and FHWSA, and the recently constructed systems at the PSA and TL/CL have been designed with the goal of achieving these PCGs. The treatment systems for two of the sites, the PSA, and TL/CL have been in operation since early 2011. Recent operating and monitoring data from the TL/CL indicate that the remediation goals have been met, and in December 2012, the RWQCB approved the shutdown of TL/CL system for rebound testing. Operating data indicate that the remediation systems at the other locations have resulted in a decrease in concentrations of COPCs in groundwater and soil vapor and are achieving hydraulic control of the plumes.

Groundwater samples were collected at least once from 124 wells in 2012 and analyzed for a variety of constituents. The results of groundwater monitoring of wells were reported to the RWQCB in the semiannual self-monitoring report for the winter of $2012^{37}$ and the summer of $2012 .^{38}$ The groundwater analytical results were generally within each well's historical range of concentrations. Samples were analyzed for one or more of the following:

- Total petroleum hydrocarbons (TPH)

- Metals

- Polychlorinated biphenyls (PCBs)

- Tritium

- Volatile organic compounds (VOCs)

- Semi-volatile organic compounds (SVOCs)

37 Stanford Linear Accelerator Center, Semi-annual Self-Monitoring Report, Winter 2012 (SLAC-I-7502A15H-038, June 2012)

38 SLAC National Accelerator Laboratory, Semi-annual Self-Monitoring Report, Summer 2012 (SLAC-I750-2A15H-039, December 2012) 


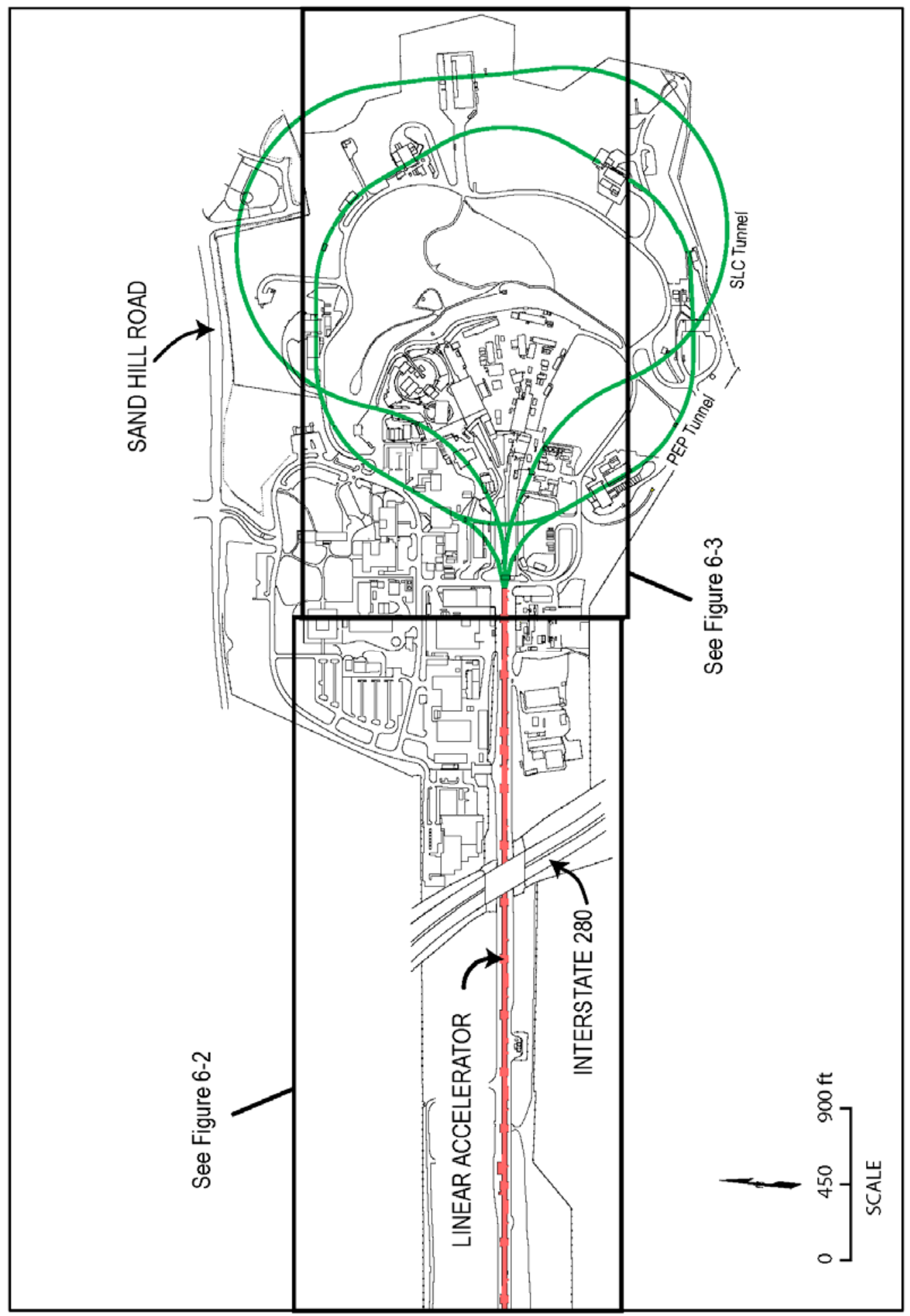

Figure 6-1 Groundwater Characterization Monitoring Network 


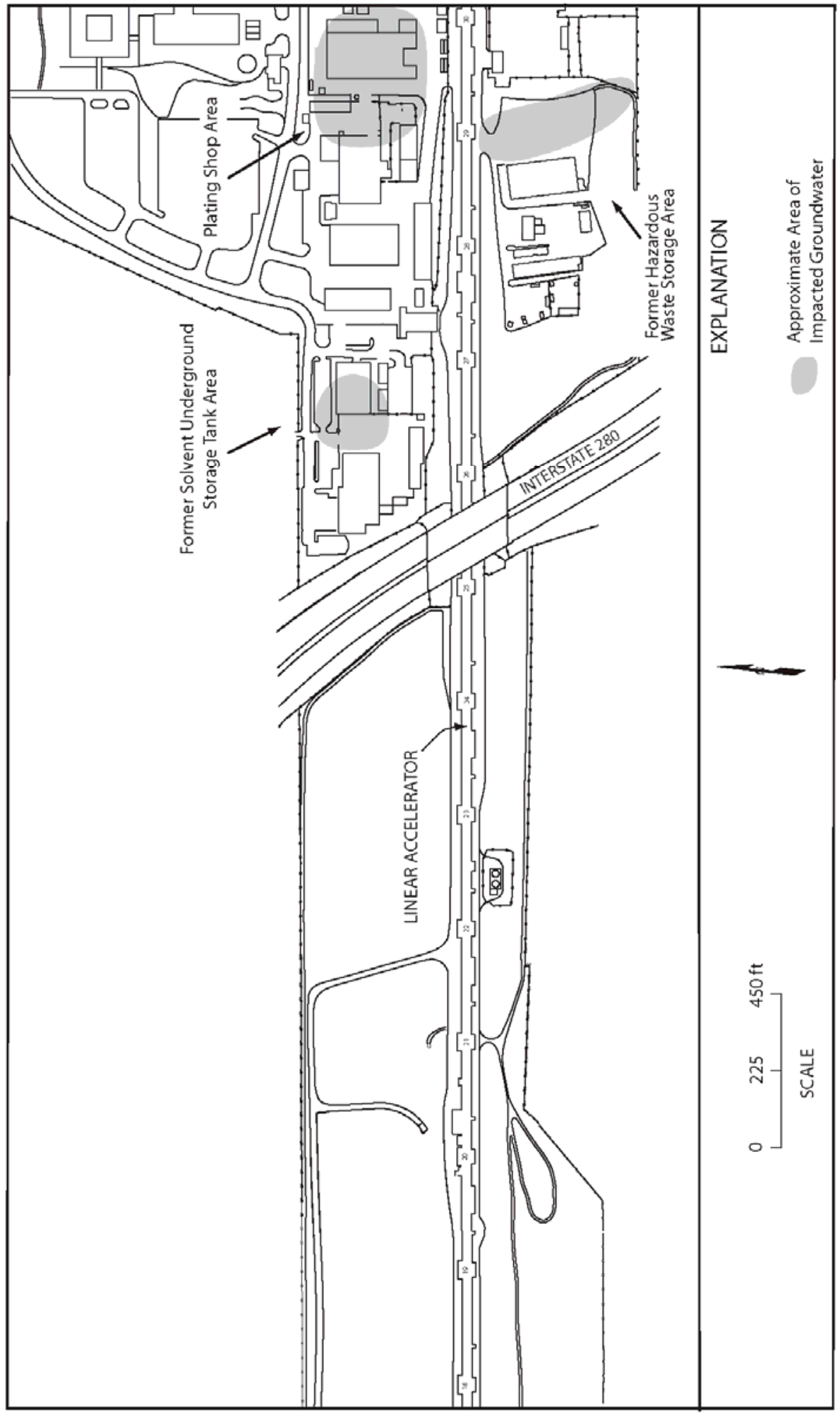

Figure 6-2 Westside Groundwater Network and Impacted Area 


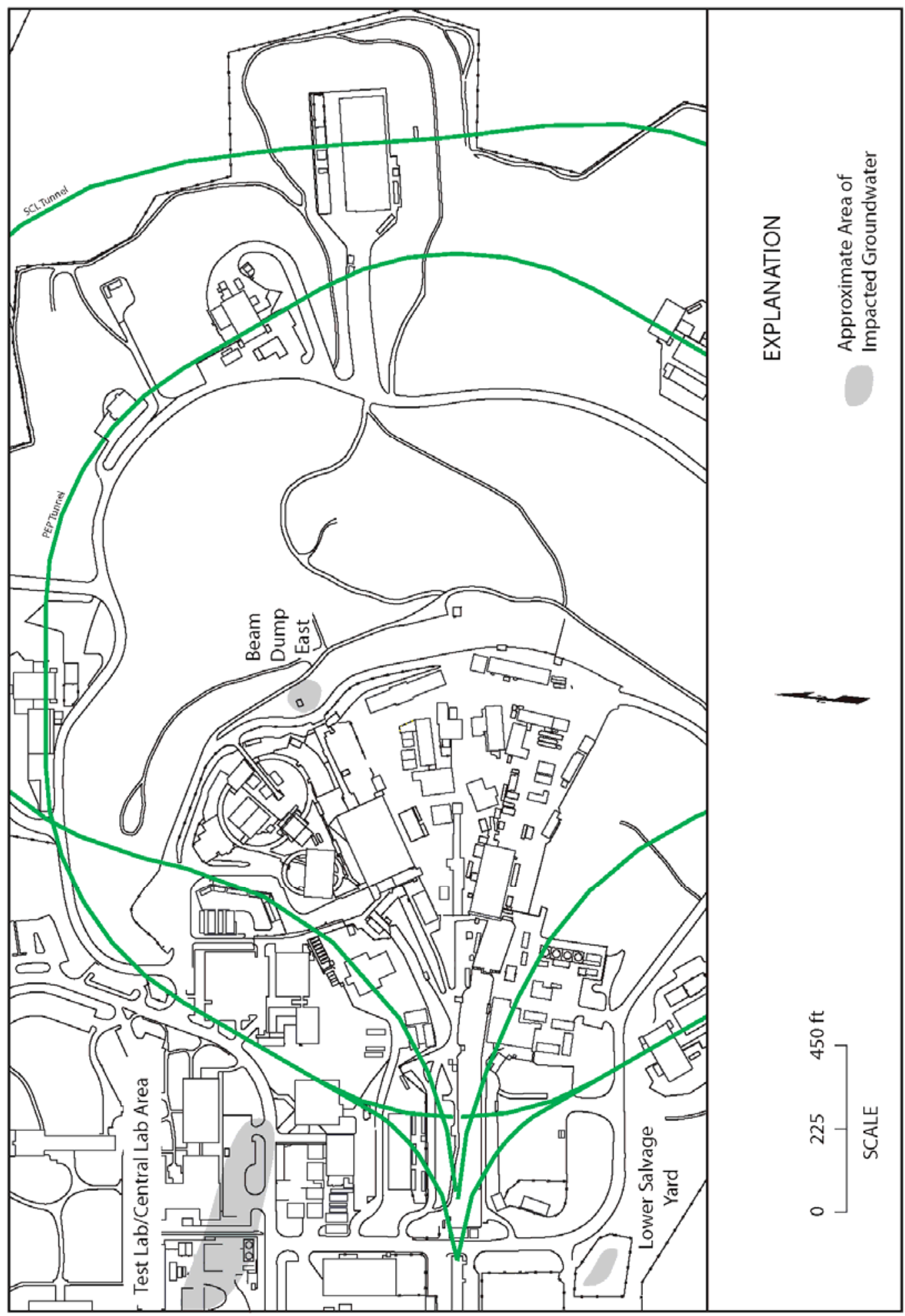

Figure 6-3 Eastside Groundwater Network and Impacted Areas 
Table 6-2 Monitoring Locations and Number of Wells

\begin{tabular}{|c|c|c|}
\hline Location & & $\begin{array}{l}\text { Number } \\
\text { of Wells }\end{array}$ \\
\hline \multicolumn{3}{|l|}{ Plume Monitoring } \\
\hline Beam Dump East & & 9 \\
\hline Former Hazardous Waste Storage Area & & 24 \\
\hline Former Solvent Underground Storage Tank & & 21 \\
\hline Lower Salvage Yard & & 4 \\
\hline Plating Shop Area & & 26 \\
\hline \multirow[t]{2}{*}{ Test Lab and Central Lab } & & 7 \\
\hline & Subtotal & 91 \\
\hline \multicolumn{3}{|l|}{ Extraction } \\
\hline Former Solvent Underground Storage Tank & & 8 \\
\hline Former Hazardous Waste Storage Area & & 23 \\
\hline Plating Shop Area & & 26 \\
\hline \multirow[t]{2}{*}{ Test Lab and Central Lab } & & 7 \\
\hline & Subtotal & 64 \\
\hline \multicolumn{3}{|l|}{ Environmental Surveillance } \\
\hline \multicolumn{3}{|l|}{ Centralized Waste Management Area } \\
\hline \multicolumn{3}{|l|}{ End Station B } \\
\hline \multicolumn{3}{|l|}{ Magnet Yard } \\
\hline \multicolumn{3}{|l|}{ Other (remote) } \\
\hline \multicolumn{3}{|l|}{ Research Yard } \\
\hline \multicolumn{3}{|l|}{ Vacuum Assembly } \\
\hline & Subtotal & 13 \\
\hline \multicolumn{3}{|l|}{ Piezometer } \\
\hline Plating Shop Area & & 4 \\
\hline \multicolumn{3}{|l|}{ Former Hazardous Waste Storage Area } \\
\hline & Subtotal & 7 \\
\hline \multicolumn{3}{|l|}{ Inactive } \\
\hline \multicolumn{3}{|l|}{ Former Solvent Underground Storage Area } \\
\hline & Subtotal & 3 \\
\hline TOTAL & & 178 \\
\hline
\end{tabular}

\subsection{Site Descriptions and Results}

The groundwater Investigation Areas are described below, including four VOC-impacted areas (TL and CL are combined) and one low-level tritium plume impacted area. Under the Board Order, the formal FS and RAP reports for the four VOC-impacted groundwater Investigation Areas were prepared by SLAC and approved by the RWQCB in January 2010 and August 2010, respectively. The RD report for the 
Groundwater VOC Operable Unit, ${ }^{39}$ which includes the four VOC-impacted plume areas, was approved by the RWQCB in March 2011, and construction of the selected remedy (DPE at the four VOC-impacted areas were completed by December 2010. Three additional Board Order deliverables were prepared and approved by the RWQCB in 2012, including:

- $\quad$ The Groundwater VOC OU RAP Implementation Report, approved in March 2012.

- The Groundwater VOC OU Operations, and Maintenance Plan, approved in May 2012 , and

- The Groundwater VOC OU Risk Management Plan, approved in April 2012.

\subsubsection{Former Solvent Underground Storage Tank Area}

A chemical plume in groundwater associated with the FSUST is located in proximity to the SLAC Plant Maintenance building in the northwestern portion of the main SLAC campus (Figure 6-2). The FSUST was used to store organic solvents from 1967 to 1978. A pressure test performed on the FSUST in 1983 indicated a leak. The FSUST and accessible chemically impacted soil were removed in December 1983. A network of 21 monitoring wells and eight extraction wells were subsequently installed, and groundwater is monitored for VOCs and SVOCs.

An interim groundwater extraction and treatment system was installed in 2001 and upgraded in 2007 with a soil vapor extraction component. The DPE operations, which started at the FSUST on October 18, 2007, increased the mass removal rate of VOCs and SVOCs from an average of 0.14 lbs per day to an average of $2.2 \mathrm{lbs}$ per day for the remainder of 2007. The average mass removal rate has since declined, as anticipated as the more concentrated sources are removed in the soil vapor.

Since the start up of the remediation system at the FSUST in August 2001 and through December 2012, the system had removed approximately $875.6 \mathrm{lbs}$ of VOCs and SVOCs from the subsurface and treated approximately 1,072,209 gallons of extracted groundwater. Monitoring well data collected thus far indicate a capture zone encompassing the entire plume has been established and chemical data indicate that the plume appears to be continually shrinking in size. Based on monitoring data, the DPE system reduced the lateral extent of the Area of Concern (AOC), or areas where remediation goals are exceeded, at the FSUST Area by approximately 62 percent in the 2011 to 2012 period, from approximately 5,600 square feet in June 2011 to approximately 2,100 square feet in May 2012.

\subsubsection{Former Hazardous Waste Storage Area}

The FHWSA was in use as a storage area from approximately 1973 to 1982. Following cessation of its use as a storage area, PCBs were found in shallow soils. As a result, several inches of topsoil were removed. A monitoring well was installed in this area in 1990, and VOCs were detected in the groundwater. Since then, two passive soil gas surveys have been performed, 22 monitoring wells, 23 DPE wells, and 18 soil gas probes have been installed, and more than 50 soil borings have been drilled at this site. Figure 6-2 shows the current extent of VOCs in the groundwater.

In 2002, a DPE pilot test proved promising to treat impacted soil and groundwater and was recommended as a suitable remediation technology. Two DPE wells were installed at the FHWSA in 2003 as part of an interim dual-phase extraction (IDPE) system. The IDPE system was in operation from December 2003 to March 2006. The design of an interim full scale DPE system for the FHWSA was finalized in $2004{ }^{40}$ and the construction of the system was completed in March 2006 after six months of construction. The full scale system utilizes 19 groundwater/soil vapor extraction wells and four vacuum-enhanced groundwater

${ }^{39}$ C/P/E, Remedial Design Report for the Groundwater VOC Operable Unit, (C/P/E SL-22GW-RPTSCD000001 R0, November 2010)

40 Erler \& Kalinowski, Technical Specifications and Drawings for the Dual Phase Extraction and Treatment System at the Former Hazardous Waste Storage Area (2004) 
extraction wells. Groundwater extraction and treatment began on March 6, 2006. Soil vapor extraction began on April 3, 2006.

The FHWSA system remained shut down from December 2011 through December 2012 as part of a planned shutdown period. The purpose of the shutdown was to evaluate whether reduced VOC concentrations in soil vapor across most of the FHWSA site are sustained in the absence of DPE and to evaluate VOC and 1,4-dioxane conditions in groundwater as water levels recover in the absence of DPE. Between start-up in December 2003 and the last day of operation on December 16, 2011, approximately 1,651,398 gallons of groundwater was extracted and total VOCs/SVOCs mass removed was 39.32 lbs by the FHWSA interim and full-scale systems, and the AOC has been reduced by approximately 92 percent as of November 2012.

\subsubsection{Plating Shop Area}

In 1990, three monitoring wells were installed down-gradient of the PSA. Chemicals of interest were detected in all three wells; and an investigation began and included installation of additional monitoring wells, a soil gas survey, and remediation beneath a steam cleaning pad. A total of 26 monitoring wells are currently located at the PSA (Figure 6-2). Groundwater sampling results indicate that chemicals are present in groundwater within three co-mingled plumes.

Construction of a 26 DPE-well system with additional soil vapor probes and monitoring wells was completed and began operation in November 2010. Four wells were constructed to be used as piezometers. Between start-up in November 2010 and the end of December 2012 approximately 1,910,152 gallons of groundwater have been extracted by the PSA DPE system. Cumulative total VOCs/SVOCs mass removed by the system was $9.68 \mathrm{lbs}$. The operating DPE system at the PSA was constructed in accordance with the RD report for the Groundwater VOC OU which was formally approved by the RWQCB in 2011. Based on operation and monitoring data, the AOC at the PSA has been reduced by 85 percent since the system startup in 2011.

\subsubsection{Test Lab and Central Lab Area}

Data from previous investigations, including a soil gas survey, soil borings and monitoring wells installed in the TL/CL have helped delineate the sources of groundwater and soil vapor impacts. Results of the investigation indicated three possible source areas for VOCs, including one adjacent to the TL, and two adjacent to the CL. The final remedial design specified two separate DPE systems at the TL/CL.

Construction of separate DPE-well systems at the TL and at the CL with additional soil vapor probes and monitoring wells was completed in November 2010. Between start-up in November 2010 and the end of December 2012 approximately 200,261 gallons of groundwater have been extracted by the TL DPE systems and 682,572 gallons of groundwater have been extracted by the CL DPE system. Cumulative total VOCs/SVOCs mass removed by the TL system was $0.77 \mathrm{lbs}$. For the CL system, cumulative total VOCs/SVOCs mass removed was 3.08 lbs. The operating DPE systems at both the TL and CL were constructed in accordance with the RD report for the Groundwater VOC OU which was formally approved by the RWQCB in 2011. As previously discussed, operating and monitoring data from the TL/CL system indicate that all remediation goals were met in late 2012 and in December 2012 the RWQCB approved the shut-down of TL/CL system for rebound testing.

\subsubsection{Beam Dump East}

The BDE was used as a subsurface high-energy beam termination point for the End Station A beamline operations and is located in the hillside along the northeastern edge of the research yard. Groundwater is monitored in nine wells and sampled at least two times per year. In 2012, as in previous years, the monitoring of groundwater indicates that the tritium is localized to two wells in the area of the beam dump and present at levels far below the drinking water standards. The BDE is part of the Tritium OU, for which a formal RI report has been prepared by SLAC under the Board Order and approved by the RWQCB in June 2009. In addition, a Monitoring Plan Report (MPR) was prepared by SLAC under the Board Order 
and approved by the RWQCB in December 2009. The MPR specifies continued groundwater monitoring at the BDE with contingent actions in the unlikely event that monitored tritium levels exceed any established threshold concentrations.

\subsubsection{Lower Salvage Yard}

Two monitoring wells were installed at the LSY during 2011. The two wells, MW-108 and MW-109 were installed to replace wells MW-26 and MW-71, respectively, which were destroyed in 2010 in preparation for the excavation at the LSY in 2011. There have been minor detections of PCBs, TPH and VOCs in wells at the LSY. Low levels of TPH and PCBs continue to be detected in groundwater samples collected at the LSY during 2012.

\subsubsection{Removal Actions}

Soil removal actions were completed at five Group I Investigation Areas (Group I IAs) in 2008 to remove debris and soil impacted with PCBs, TPH, polycyclic aromatic hydrocarbons and/or metals at concentrations above Preliminary Remediation Goals (PRGs) or pre-established cleanup goals. Following the removal action work, the Group 1 Removal Action Implementation Report was prepared by SLAC and approved by the RWQCB in April 2009. This report documents the excavation and removal of approximately 5,000 tons of chemically impacted soil and debris from the five areas at SLAC. The report includes a residual risk evaluation and forms the basis for proceeding to the closure process for these specific areas. In 2011, SLAC completed preparation of Closure Summary Packages for the five Group 1 investigation areas and in August 2011, the RWQCB provided approval of the Closure Packages. These closure packages provided the requisite documentation to support the cleanup and site closures at SLAC. The RWQCB approval of these site closures are the first for SLAC and represent the culmination of several years of collaborative work among DOE, Stanford University, SLAC, and the RWQCB.

In 2008, the DOE awarded a contract to C/P/E Environmental Services, LLC, of Atlanta, Georgia (CPE), to help perform soil removal cleanup actions at SLAC. The task order had the primary performance objective of restoring the work areas to conditions that are protective of human health and the environment. The soil removal actions were performed based on an Engineering Evaluation and Cost Analysis and in advance of the formal FS report for the West SLAC OU. CPE completed soil removal actions at 14 areas within SLAC. As of the end of 2012, these areas included the FHWSA-Artificial Ridge, Clean Landfill Area, Bone Yard, Building 24 and Building 34 Area, LSY, Sector 16 Soil Relocation Area Drainage Swale, the Casting Pad \& Building 18 Area, select Klystron Gallery Variable Voltage Substation Areas, Sector 16 Storage Area Drainage Channel, IR-6 Secondary Drainage Channel, Building 007 Area, IR-8 Fill Area, IR8 Landscape Strip Area, and Upper Salvage Yard Area. These removal actions resulted in the removal of approximately 35,000 cubic yards of impacted soil and debris from the 14 areas. A draft Closure Report for the Group 2 Removal Action Site was prepared and submitted for RWQCB review and approval in December 2012.

\subsection{Excavation Clearance Program}

During 2012, the excavation clearance program continued to support SLAC-wide projects to ensure proper disposal of excavated soil. An excavation permit form must be completed for activities that involve excavation or relocation of soil at SLAC. The permitting process is intended to identify potential hazards associated with excavation work at SLAC. The excavation clearance program addresses potential worker exposure hazards associated with underground utility lines, chemical contamination, and radiological hazards. The program also ensures proper management and disposal of excavated materials. Forty-two projects were supported by this program during 2012. 


\section{A Distribution List}

\begin{tabular}{|c|c|c|c|}
\hline Name & Title & Organization & E-mail \\
\hline Andrew Lawrence & Director & $\begin{array}{l}\text { HS-20, Office of Environmental } \\
\text { Protection, Sustainability Support } \\
\& \text { Corporate Safety Analysis }\end{array}$ & \\
\hline Andrew Wallo, & Deputy Director & $\begin{array}{l}\text { HS-20, Office of Environmental } \\
\text { Protection, Sustainability Support } \\
\text { \& Corporate Safety Analysis. }\end{array}$ & \\
\hline Sat Goel & Office of Science & $\begin{array}{l}\text { SC-31, Office of Safety, Security } \\
\text { and Infrastructure }\end{array}$ & \\
\hline Marc Jones & $\begin{array}{l}\text { Office of Science, } \\
\text { Associate Director }\end{array}$ & $\begin{array}{l}\text { SC-31, Office of Safety, Security } \\
\text { and Infrastructure }\end{array}$ & \\
\hline $\begin{array}{l}\text { Katatra Vasquez } \\
\text { David Allen }\end{array}$ & & $\begin{array}{l}\text { Integrated Support Center, Oak } \\
\text { Ridge Office }\end{array}$ & \\
\hline & & $\begin{array}{l}\text { Integrated Support Center, Oak } \\
\text { Ridge Office }\end{array}$ & \\
\hline Edward Regnier & Office of Science & $\begin{array}{l}\text { HS-2, Office of Environmental } \\
\text { Policy and Assistance }\end{array}$ & \\
\hline Rosario Natoli & & $\begin{array}{l}\text { HS-22, Office of Environmental } \\
\text { Policy and Assistance }\end{array}$ & ross.natoli@hq.doe.gov \\
\hline Paul Golan & Site Manager & SLAC Site Office & \\
\hline Hanley Lee & $\begin{array}{l}\text { Deputy Site } \\
\text { Manager }\end{array}$ & SLAC Site Office & Hanley.lee@sso.science.doe.gov \\
\hline Tom Rizzi & EFO Team Lead & SLAC Site Office & Thomas.rizzi@sso.science.doe.gov \\
\hline Dave Osugi & EFO & SLAC Site Office & David.osugi@sso.science.doe.gov \\
\hline Annette Walton & $\begin{array}{l}\text { Environmental } \\
\text { Manager }\end{array}$ & Office of Stanford Real Estate & nettie@stanford.edu \\
\hline Allan Chiu & Permit Engineer & $\begin{array}{l}\text { Bay Area Air Quality Management } \\
\text { District }\end{array}$ & achiu@baaqmd.gov \\
\hline Gary Butner & Acting Director & $\begin{array}{l}\text { California Department of Health } \\
\text { Services, Radiologic Health } \\
\text { Branch }\end{array}$ & gbutner@dhs.ca.gov \\
\hline George Leyva & & $\begin{array}{l}\text { Regional Water Quality Control } \\
\text { Board, San Francisco Bay Region }\end{array}$ & gleyva@waterboards.ca.gov \\
\hline Dean Peterson & & $\begin{array}{l}\text { San Mateo County Department of } \\
\text { Health Services, Office of } \\
\text { Environmental Health }\end{array}$ & dpeterson@co.sanmateo.ca.us \\
\hline Glen Rojas & City Manager & City of Menlo Park & grojas@menlopark.org \\
\hline $\begin{array}{l}\text { Magaly Bascones } \\
\text { Dominguez }\end{array}$ & & CERN. Library, Periodicals Unit & $\frac{\text { Magaly.bascones.dominguez }}{@ \text { cern.ch }}$ \\
\hline
\end{tabular}

